\title{
Frequent lack of repressive capacity of promoter DNA methylation identified through genome-wide epigenomic manipulation
}

\author{
Ethan Ford ${ }^{1}$, Matthew R. Grimmer ${ }^{2,3,4}$, Sabine Stolzenburg ${ }^{5}$, Ozren Bogdanovic ${ }^{1,6,7}$, Alex de \\ Mendoza $^{1}$, Peggy J. Farnham², Pilar Blancafort ${ }^{5,8}$, Ryan Lister ${ }^{1,8}$ *
}

\section{Affiliations:}

${ }^{1}$ Australian Research Council Centre of Excellence in Plant Energy Biology, School of Molecular Sciences, The University of Western Australia, 35 Stirling Hwy, Crawley, WA 6009, Australia.

${ }^{2}$ Department of Biochemistry and Molecular Medicine, University of Southern California, 1450 Biggy St, Los Angeles, CA 90089, USA.

${ }^{3}$ Integrated Genetics and Genomics, University of California, Davis, 451 Health Sciences Dr, Davis, CA 95616, USA.

${ }^{4}$ Department of Neurological Surgery, University of California, San Francisco, 1450 3rd St, San Francisco, CA 94158, USA.

${ }^{5}$ School of Anatomy, Physiology and Human Biology, The University of Western Australia, 35 Stirling Hwy, Crawley, WA 6009, Australia.

${ }^{6}$ Genomics and Epigenetics Division, Garvan Institute of Medical Research, Sydney, New South Wales, Australia.

${ }^{7}$ St Vincent's Clinical School, Faculty of Medicine, University of New South Wales, Sydney, New South Wales, Australia.

${ }^{8}$ Harry Perkins Institute of Medical Research, 6 Verdun St, Nedlands, WA 6009, Australia.

${ }^{*}$ Corresponding author. Email: ryan.lister@uwa.edu.au (R.L.) 
Abstract: It is widely assumed that the addition of DNA methylation at CpG rich gene promoters silences gene transcription. However, this conclusion is largely drawn from the observation that promoter DNA methylation inversely correlates with gene expression in natural conditions. The effect of induced DNA methylation on endogenous promoters has yet to be comprehensively assessed. Here, we induced the simultaneous methylation of thousands of promoters in the genome of human cells using an engineered zinc finger-DNMT3A fusion protein, enabling assessment of the effect of forced DNA methylation upon transcription, histone modifications, and DNA methylation persistence after the removal of the fusion protein. We find that DNA methylation is frequently insufficient to transcriptionally repress promoters. Furthermore, DNA methylation deposited at promoter regions associated with $\mathrm{H} 3 \mathrm{~K} 4 \mathrm{me} 3$ is rapidly erased after removal of the zinc finger-DNMT3A fusion protein. Finally, we demonstrate that induced DNA methylation can exist simultaneously on promoter nucleosomes that possess the active histone modification $\mathrm{H} 3 \mathrm{~K} 4 \mathrm{me}$, or DNA bound by the initiated form of RNA polymerase II. These findings suggest that promoter DNA methylation is not generally sufficient for transcriptional inactivation, with implications for the emerging field of epigenome engineering.

One Sentence Summary: Genome-wide epigenomic manipulation of thousands of human promoters reveals that induced promoter DNA methylation is unstable and frequently does not function as a primary instructive biochemical signal for gene silencing and chromatin reconfiguration. 
Main Text: While the mammalian genome is almost entirely methylated at cytosines in the CpG dinucleotide context $(\mathrm{mCG})(1)$, regulatory regions such as $\mathrm{CpG}$ rich promoters and active enhancers generally exhibit a low- or un-methylated state (2, 3). However, a broader understanding of whether DNA methylation at such regions is generally causative for transcriptional silencing has remained elusive. DNA methylation of gene promoters is frequently inversely correlated with transcriptional activity $(2,4,5)$, and abolition of DNA methyltransferase activity through chemical inhibition or genetic disruption causes global demethylation and activates numerous genes $(6,7)$. Such observations have led to the common conclusion that DNA methylation of $\mathrm{CpG}$ island (CGI) promoters and other regulatory sequences causes transcriptional silencing. However, these observations are correlative and challenging to interpret because genome-wide demethylation could have widespread and complex downstream effects upon chromatin structure and gene expression. Transfection and microinjection of differentially methylated sequences have demonstrated a repressive role of DNA methylation, but may not accurately reproduce the chromatin state and other regulatory processes of endogenous promoters (8-10). Moreover, DNA methylation has been reported to occur downstream of transcriptional regulation in some contexts. In early development and germline cells, transcription can occur from genes with methylated promoters (11-13). Furthermore, transcriptional silencing can precede the acquisition of promoter DNA methylation (14), including genes on the female inactive $X$ chromosome $(15,16)$ and imprinted genes during development (17). Finally, while aberrant promoter CGI hypermethylation is observed at many silenced genes in cancers, these genes are frequently already repressed in normal preneoplastic cells $(18,19)$. Thus, whether DNA methylation at promoters generally functions as a primary instructive biochemical signal for gene silencing remains unresolved. 
Targeted methods to alter methylation state at endogenous loci have been developed in recent years, including customized zinc finger (ZF) domains fused to the catalytic domain of human DNA methyltransferase 3A (ZF-DNMT3A) (20-25) or the bacterial methyltransferase M.SssI (26), and more recently the fusion of DNMT3A to transcription activator-like effector (TALE) proteins or nuclease inactive Cas9 (27-32). These artificial epigenome modifiers allow targeted interrogation of whether DNA methylation correlates with, or is causative for, transcriptional repression. Their application at a few tested loci has indicated that induction of methylation on promoters is sometimes sufficient to repress transcription. Indeed, DNMT3B-mediated targeted induction of DNA methylation at an artificial promoter and reporter locus in mammalian ( $\mathrm{CHO})-\mathrm{K} 1$ cells was sufficient to cause stable transgene silencing (33). However, a broad examination of the capacity of induced DNA methylation of endogenous promoters in the mammalian genome to cause changes in gene expression and chromatin has not previously been undertaken.

Given the efficient post-replicative maintenance of DNA methylation patterns by DNMT1 (34), DNA methylation has been implicated in long-term gene silencing (35). However, the stability of targeted induced methylation appears to be variable, with examples of both stable (36) and transient $(24,30)$ methylation and silencing of different genes. Thus, the context in which DNA methylation is sufficient to establish transcriptional repression and the stability of induced DNA methylation has not been broadly characterized. The function of changes in DNA methylation observed in differentiation, development and disease are very challenging to interpret without a clear determination of whether the addition of DNA methylation to diverse regulatory regions is sufficient to induce transcriptional silencing. To address this, we undertook a broad assessment of the consequences upon gene expression and chromatin state of inducing DNA methylation at promoter regions throughout the human genome. 
Genome-wide epigenomic manipulation. We took advantage of a cell line derived from human breast adenocarcinoma MCF-7 cells that, upon doxycycline treatment, expresses an artificial epigenome modifier composed of 6 zinc finger (ZF) domains linked to the catalytic domain of human DNMT3A (25) (ZF-D3A, Fig. 1A). The ZF array was designed to bind to a GC-rich 18 bp sequence in a CGI in the SOX2 promoter, as confirmed by ChIP-seq of the HA-epitope-tagged ZF-D3A protein (Fig. 1B). To assess the effect of ZF-D3A expression upon DNA methylation states throughout the genome, we performed whole genome bisulfite sequencing (WGBS) of 1) control MCF-7 cells harboring an integrated empty vector construct and grown in the presence of doxycycline for 3 days (MCF7-control) to establish baseline methylation levels, 2) MCF7-ZF-D3A cells induced with doxycycline for 3 days (ZF-D3A +dox), and 3) MCF7-ZF-D3A cells induced with doxycycline for 3 days then subsequently grown in doxycycline-free media for 9 days after doxycycline withdrawal (ZF-D3A dox-wd). The weighted CG methylation level (see methods) of the SOX2 promoter was $34 \%$ higher in ZF-D3A +dox compared to MCF7-control, and approximately half of the induced methylation remained in ZF-D3A dox-wd cells (Fig. 1B). RNA-seq analysis revealed that the induction of methylation was associated with a 2.5 fold decrease in SOX2 mRNA relative to MCF7-control cells, which was sustained after doxycycline withdrawal (Fig. 1B). Thus, ZF-D3A methylates its target region and results in repression of the SOX2 gene.

However, ZF domains have a propensity to bind to sequences similar to their intended target (37), and to GC-rich sequences in general (38). Given the GC-rich characteristics of the intended target site within a $\mathrm{CGI}$ in the SOX2 promoter, and the prevalence of $\mathrm{CpG}$-rich regulatory regions (e.g. CGls, gene promoters), the ZF-D3A protein could potentially bind to and deposit DNA methylation broadly at CpG-rich regulatory regions throughout the genome. 
Indeed, analysis of the localization of HA-tagged ZF-D3A protein by ChIP-seq in ZF-D3A +dox cells identified 25,142 off-target binding sites throughout the genome (FDR $<0.05$ ), primarily in promoters, gene bodies, and intergenic regions (Fig. 1C, table S1). Therefore, this system enables the effect of induced DNA methylation to be assessed at many thousands of regulatory regions simultaneously, rather than laboriously testing one at a time.

Global methylation levels in the $\mathrm{CH}(\mathrm{H}=\mathrm{A}, \mathrm{C}$ or $\mathrm{T})$ sequence context in both MCF7-control and ZF-D3A +dox cells was equal to the bisulfite non-conversion rate $(0.5 \%)$, indicating that the ZF-D3A fusion protein did not significantly alter $\mathrm{CH}$ methylation in the genome. In contrast, global CG methylation levels were $5.2 \%$ higher in ZF-D3A +dox cells (68.2\%) compared to MCF7-control (63\%). Consequently, further analyses focused on CG methylation. We identified 10,356 differentially methylated regions (DMRs) in the CG dinucleotide context between MCF7-control and ZF-D3A +dox, located in gene promoters (38\%; $\pm 2 \mathrm{~kb}$ of a transcriptional start site), gene bodies (27\%), putative enhancers $(6 \%$; H3K4me1/H3K27ac modified chromatin), and intergenic regions not corresponding to enhancers (30\%; Fig. 1D, table S2). Notably, only 35\% of DMRs intersected with ZF-D3A ChIP-seq peaks. While there was an enrichment of ZF-D3A binding in the majority of DMRs, particularly those in CpG-rich promoters, many DMRs showed no detectable interaction with ZF-D3A (Fig. 1E), suggesting that ZF-D3A may induce methylation in the absence of apparent strong and persistent protein binding. The binding sites of the ZF-D3A fusion protein in ZF-D3A +dox cells exhibited a wide range of initial methylation states in MCF7-control cells, with unmethylated and partially methylated regions frequently gaining methylation when the fusion protein was expressed in ZF-D3A +dox cells (Fig. 1F).

In addition to DMR detection, we defined the boundaries of unmethylated regions (UMRs, (39)) of the genome flanked by methylated DNA in MCF7-control cells, which frequently 
encompass gene promoters. This enables measurement of the DNA methylation induced across an entire gene promoter, as opposed to potentially only a subset of it, as is possible with DMRs. In MCF7-control cells 15,911 UMRs were identified (see methods), with most (77\%) within $2 \mathrm{~kb}$ of a transcriptional start site and 82\% overlapping with CGls (Fig. 1G, table S3). UMRs and DMRs frequently overlapped, with approximately one third of each type of region intersecting with the other (Fig. 1H). Both UMRs and DMRs were used to assess the effects of the widespread binding and induction of DNA methylation by ZF-D3A.

The level and stability of DNA methylation induced by ZF-D3A was assessed by comparing the methylation level in each DMR (mCG/CG: the ratio of $\mathrm{C}$ base calls to total base calls for all CG dinucleotides in the region) between MCF7-control, ZF-D3A +dox, and ZF-D3A dox-wd cells (Fig. 2, A to C). The DNA methylation level was higher in ZF-D3A +dox cells compared to MCF7-control in $99.9 \%$ of DMRs, while widespread loss of the induced methylation in the DMRs was observed in ZF-D3A dox-wd (fig. S1A). To assess whether retention of induced DNA methylation in DMRs correlated with the baseline level of methylation in the absence of ZF-D3A, we focussed on DMRs with either low $(<0.1)$ or high $(>0.3)$ initial methylation levels in MCF7-control cells. After doxycycline induction and subsequent withdrawal in ZF-D3A cells, $66 \%$ of DMRs that had low initial methylation levels returned to baseline levels after doxycycline withdrawal $(\Delta \mathrm{mCG}<0.1$, where $\triangle \mathrm{mCG}=$ difference in methylation level between ZF-D3A dox-wd and MCF7-control; Fig. 2, A and C, fig. S1A). In contrast, only 8\% of DMRs with high initial DNA methylation levels returned to their initial levels $(\triangle \mathrm{mCG}<0.1)$ after doxycycline withdrawal. DMRs that lost induced methylation tended to be CpG-rich and located at promoters, whereas induced DNA methylation was generally more stable at CpG-poor non-promoter genomic regions that were initially partially methylated (fig. S1A). Indeed, assessment of UMRs showed that upon expression of ZF-D3A, 68\% of UMRs gained 
methylation $(\triangle \mathrm{mCG}>0.1)$, however nearly all UMRs lost the induced DNA methylation in the ZF-D3A dox-wd cells (Fig. 2, D to F). Therefore, UMRs are inherently resistant to the stable maintenance of artificially induced DNA methylation.

As most UMRs are located in promoter regions and at CGIs (Fig. 1G), we assessed the association of all DMRs with different active chromatin states to determine whether particular histone modifications and functional genomic regions were associated with the stable or transitory nature of induced DNA methylation. ChIP-seq of H3K4me3 in ZF-D3A no-dox cells revealed that DMRs enriched for $\mathrm{H} 3 \mathrm{~K} 4 \mathrm{me} 3$, which are also $\mathrm{CpG}$-rich and located in promoters, are largely demethylated to baseline levels upon doxycycline withdrawal, whereas DMRs not enriched for H3K4me3 exhibit higher retention of DNA methylation (Fig. 2G). Specifically, 78\% of the top quartile of DMRs, sorted by the highest H3K4me3 signal in ZF-D3A no-dox cells, returned to similar methylation levels $(\triangle \mathrm{mCG}<0.1)$ in ZF-D3A dox-wd. In contrast, only $14 \%$ of the bottom quartile of $\mathrm{H} 3 \mathrm{~K} 4 \mathrm{me} 3$ sorted DMRs returned to initial methylation levels $(\Delta \mathrm{mCG}<0.1)$ after doxycycline withdrawal.

To determine whether induced DNA methylation was also transitory at regions marked with other active histone modifications, such as $\mathrm{H} 3 \mathrm{~K} 4 \mathrm{me} 1$ and $\mathrm{H} 3 \mathrm{~K} 27 \mathrm{ac}$ that are enriched at enhancers, we ranked the DMRs not associated with H3K4me3 by their level of H3K4me1 enrichment (Fig. 2H). The association between H3K4me1 enrichment and loss of induced DNA methylation was far less pronounced than for H3K4me3. Specifically, $9.6 \%$ of DMRs in the top quartile of $\mathrm{H} 3 \mathrm{~K} 4 \mathrm{me} 1$ enrichment returned to near-baseline levels of DNA methylation ( $\Delta \mathrm{mCG}$ $<0.1$ ) in ZF-D3A dox-wd, compared to $3.2 \%$ in the bottom quartile. Thus, artificially induced methylation exhibits higher stability at H3K4me1 modified loci. 
Forcibly methylated DNA associates with active chromatin marks and transcription. DNA methylation and $\mathrm{H} 3 \mathrm{~K} 4 \mathrm{me} 3$ are, for the most part, mutually exclusive marks in CpG-rich regions (40), and H3K4me3 may protect against cytosine methylation (41). However, it is not known whether forced $\mathrm{mC}$ deposition is sufficient to induce the loss of $\mathrm{H} 3 \mathrm{~K} 4 \mathrm{me}$. Analysis of $\mathrm{H} 3 \mathrm{~K} 4 \mathrm{me} 3$ ChIP-seq read density between ZF-D3A cells not treated with doxycycline (ZF-D3A no-dox) and ZF-D3A +dox cells, at genomic regions flanking all 10,356 DMRs with a $\Delta$ mCG $>0.2$, revealed a small decrease (median 0.7-fold) in H3K4me3 signal after induction of ZF-D3A (Fig. 3, A and B, fig. S1B). To account for variations in ChIP efficiency, the two ChIP-seq data sets were normalized by the number of reads mapped to $\mathrm{H} 3 \mathrm{~K} 4 \mathrm{me} 3$ peaks that had a $\triangle \mathrm{mCG}<0.2$ between ZF-D3A no-dox and ZF-D3A +dox cells (Fig. 3A, bottom). While DMRs only exhibit a $\Delta$ mCG of $>0.2$ upon doxycycline induction, UMRs display a broad range of induced methylation, with many that are not methylated by ZF-D3A, therefore we assessed the correlation between H3K4me3 level and DNA methylation in UMRs. Notably, there is no correlation between the change in DNA methylation and the level of H3K4me3 in UMRs (Fig. 3C). This suggests that the small decrease of H3K4me3 occupancy observed in ZF-D3A +dox cells at DMRs is not a result of induced DNA methylation, indicating that DNA methylation has minimal, if any, effect on H3K4me3 modification.

Because of the limited sensitivity of ChIP-seq and the possibility that there could be a heterogeneous population of loci with methylated and unmethylated DNA molecules, we directly measured the DNA methylation level in H3K4me3-modified chromatin using ChIP-bisulfite-sequencing (42-44). For this analysis UMRs were favored over DMRs, since UMRs span the entire unmethylated promoter region. We identified 6,392 H3K4me3 ChIP-seq peaks from both ZF-D3A +dox and ZF-D3A no-dox cells that overlapped with UMRs exhibiting a $\Delta \mathrm{mCG}>0.2$ across the entire UMR upon induction of the ZF-D3A fusion protein. In DNA purified 
by H3K4me3 ChIP in ZF-D3A +dox, 21\% of CpGs within the 6,392 H3K4me3 peaks were methylated, demonstrating that $\mathrm{H} 3 \mathrm{~K} 4 \mathrm{me} 3$ and DNA methylation can exist simultaneously at the same site upon forced induction of DNA methylation (Fig. 3D).

Promoter DNA methylation has been proposed to inhibit transcription, thus we investigated whether the initiated form of RNA polymerase II (phosphorylated at Serine 5 of the CTD; phospho-Ser5) was able to bind DNA methylated by ZF-D3A, by ChIP-bisulfite-sequencing (12) of genomic DNA isolated with an anti-phospho-Ser5 RNA polymerase II antibody. We analyzed UMRs that exhibited a $\triangle \mathrm{mCG}>0.2$ between ZF-D3A no-dox and ZF-D3A +dox cells and that intersected with phospho-Ser5 RNA pol II ChIP-seq peaks. Similar to $\mathrm{H} 3 \mathrm{~K} 4 \mathrm{me}$, there was only a small decrease in the median DNA methylation level between DNA bound by phospho-Ser5 RNA pol II (29\%) and non-immunoprecipitated bulk genomic DNA (23\%). Importantly, phospho-Ser5 RNA pol II was clearly able to directly interact with ZF-D3A methylated DNA (Fig. 3E). Together, these data demonstrate that forced DNA methylation is not sufficient to disrupt $\mathrm{H} 3 \mathrm{~K} 4 \mathrm{me} 3$ occupancy or the interaction of initiated RNA polymerase II with genomic DNA.

Induced DNA methylation is is actively demethylated. To gain insights into the durability of induced DNA methylation after removal of ZF-D3A, DNA methylation and HA-tagged ZF-D3A protein levels were quantitated throughout doxycycline induction and subsequent withdrawal. ZF-D3A protein was strongly expressed 1 day after doxycycline addition and returned to undetectable/baseline levels 1 day after doxycycline withdrawal (Fig. 4A). The band visible at the same molecular weight as ZF-D3A prior to induction (Fig. 4A) is a non-specific protein, as indicated by the extremely similar DNMT3A mRNA levels in MCF7-control and ZF-D3A cells in the absence of doxycycline, and negligible ZF mRNA in ZF-D3A cells without doxycycline and 
following its withdrawal (fig. S2A). Moreover, any potential basal expression of ZF-D3A had no discernible effect on DNA methylation levels, as revealed by the very similar DMR methylation levels between MCF7-control and ZF-D3A cells without doxycycline (fig. S2B). Furthermore, PCA of RNA-seq data from MCF7-control, ZF-D3A no-dox and ZF-D3A +dox cells showed that most variance is explained by PC1 (83\%), and this component clearly separates ZF-D3A +dox cells from MCF7-control and ZF-D3A no-dox, while PC2 only explains $10 \%$ of the variance and differentiates between MCF-control and ZF-D3A no-dox. Thus, MCF7-control and ZF-D3A no-dox cells are much more similar to one another than to ZF-D3A +dox cells (fig. S2C).

Targeted bisulfite sequencing analysis of DNA methylation dynamics at several representative promoters exhibiting strongly induced methylation upon ZF-D3A induction showed that the robust increase in DNA methylation under ZF-D3A induction returned to near-baseline levels 5 days after the removal of doxycycline (Fig. 4B, fig. S3 A to F). Thus, both WGBS (Fig. 2, A and C) and targeted bisulfite sequencing analyses demonstrated that forced DNA methylation by ZF-D3A is rapidly removed in the absence of the ZF-D3A protein.

The loss of induced DNA methylation following removal of ZF-D3A could be the result of passive loss by lack of its maintenance after DNA replication, or active removal by a mechanism such as TET dioxygenase-mediated demethylation (45). To determine whether DNA methylation loss occurred through an active or passive process, we grew ZF-D3A cells in the presence of doxycycline for 3 days, after which the media was changed to doxycycline-free media containing different cell cycle inhibitors at concentrations previously shown to be effective in MCF7 cells (Lovastatin - G1 block; thymidine - S-phase block) or HeLa cells (RO-3306 - G2/M block) (46-48). To assess the cell cycle inhibitor efficacies, ZF-D3A cells were treated with each drug for 48 hours and the percentage of cells in $\mathrm{G} 1, \mathrm{~S}$ and $\mathrm{G} 2 / \mathrm{M}$ phases of the cell cycle quantified. Lovastatin treatment resulted in an increase in the percentage of cells in G1 from 
$44.4 \%$ to $71.5 \%$, while RO-3306 resulted in an increase from $24.2 \%$ to $57.1 \%$ of cells in G2/M. While thymidine caused a decrease in the percentage of cells in S-phase, a clear shift within S-phase to cells near the S-G2 transition as compared to the untreated cells was observed (fig. S4, A and B). Importantly, despite this disruption of cell cycle progression, these compounds had negligible effect upon DNA methylation loss (Fig. 4C, fig. S4C). For example, after 5 days of doxycycline withdrawal, $88-100 \%$ of the induced DNA methylation at the 7 loci analyzed was lost in the cells treated with the three cell cycle inhibitors, compared to the untreated cells, demonstrating that DNA methylation deposited by ZF-D3A is actively removed.

The most thoroughly documented active DNA demethylation mechanism operates via the TET family of dioxygenase proteins, which proceed through a 5-hydroxymethylcytosine (hmC) intermediate (49). To assess whether forced methylation was subjected to TET-mediated demethylation, sites of $\mathrm{hmC}$ were identified genome-wide by TET-Assisted-Bisulfite-sequencing (TAB-seq) (50) in MCF7-control and ZF-D3A +dox cells. A significant increase in hmC levels in the DMRs ( $p$-value $<2.2 \times 10^{-16}$, Wilcoxon signed rank test) was observed in ZF-D3A +dox (Fig. 4D, fig. S1B). A significant enrichment in $\mathrm{hmC}$ ( $\mathrm{p}$-value $<2.2 \times 10^{-16}$, Wilcoxon signed rank test) occurred precisely at the DMRs compared to flanking $( \pm 2.5 \mathrm{~kb})$ genomic regions in ZF-D3A + dox cells, whereas no significant enrichment was observed ( $p$-value 0.29 , Wilcoxon signed rank test) in the same regions in MCF7-control cells (Fig. 4E and fig. S3G). Notably, DMRs with the highest hmC levels were depleted in $\mathrm{H} 3 \mathrm{~K} 4 \mathrm{me} 3$ in ZF-D3A +dox cells, suggesting that $\mathrm{H} 3 \mathrm{~K} 4 \mathrm{me} 3$ may stimulate further oxidation of $\mathrm{hmC}$ to 5-formylcytosine and 5-carboxylcytosine (Fig. 4D). A small subset of DMRs (12\%) exhibited no hmC under any condition, and no H3K4me3 (average read depth $<1$ ), suggesting that an $\mathrm{hmC}$-independent process may demethylate some loci. Taken together with the observation that the loss of ZF-D3A induced 
methylation does not require DNA replication, this strongly implicates TET-mediated active removal of induced methylation at most DMRs.

\section{Forced promoter methylation is frequently insufficient for transcriptional silencing.}

Promoter DNA methylation induced by artificial epigenome modifiers fused to DNMT3A were previously reported to downregulate transcription, and have been proposed as therapeutic systems for silencing disease-associated genes $(22,23,25)$. However, the efficacy of targeted DNA methylation-induced silencing and the fraction of genes at which forced DNA methylation is sufficient to induce silencing are unknown. We compared the increase in DNA methylation at UMRs located within $2 \mathrm{~kb}$ of transcriptional start sites of expressed genes (>20 mapped reads) with the steady state mRNA levels of the corresponding genes in cells expressing or not expressing ZF-D3A (Fig. 5A, table S4). Of the expressed genes associated with UMRs that are robustly methylated $(\Delta \mathrm{mCG}>0.3, \mathrm{n}=2,063)$ upon ZF-D3A induction, 37\% showed either no decrease or a gain in mRNA abundance in ZF-D3A +dox cells (Fig. 5, B [blue columns] and C, fig. S5), while a further $21 \%$ exhibited only small decreases (0.7-0.9 fold) in expression (Fig. 5B, green columns) and $42 \%$ showed modest to strong repression (Fig. 5B [red columns], mRNA abundance ratio $[\mathrm{ZF}-\mathrm{D} 3 \mathrm{~A}+\mathrm{dox} / \mathrm{MCF} 7-\mathrm{control}]<0.7)$. No correlation was evident between the ability of ZF-D3A to repress transcription and the expression level of the gene (fig. S6, A and B, upper panels), the number of CpG dinucleotides in the UMR (fig. S6, A and B, middle panels), or the CpG dinucleotide density in the UMR (fig. S6, A and B, lower panels). Thus, induced DNA methylation of promoters is frequently insufficient as a primary instructive biochemical signal for gene silencing in these cells.

Because ZF-D3A does not induce 100\% methylation of all CpGs throughout the UMRs, there exists the possibility that two distinct populations of cells are being analyzed: one in which 
a promoter remains unmethylated and the associated gene is not repressed, and another in which the promoter of the gene is methylated and the gene is silenced. To address this, we performed RNA-fluorescence in-situ hybridization (RNA-FISH) with probes to the GAPDH and PSME1 mRNAs in ZF-D3A +dox cells. These two genes were selected for closer scrutiny because they had UMRs that were strongly methylated by ZF-D3A and showed no reduction in mRNA levels upon ZF-D3A expression (Fig. 5C). ZF-D3A +dox cells were sorted by FACS into high and low expressing subpopulations based on GAPDH or PSME1 RNA-FISH signal. Notably, for both genes the unsorted cells showed a unimodal distribution of target transcript abundance, as opposed to two distinct subpopulations which would be expected if only a subpopulation of cells were gaining DNA methylation (Fig. 6, A and B). FACS reanalysis of the sorted cells (Fig. 6, A and B), in addition to RT-qPCR (GAPDH) or RNA-seq (PSME1) (Fig. 6, C and D), demonstrated that RNA-FISH was effective for isolating subpopulations of cells exhibiting high and low levels of the targeted mRNA. Targeted bisulfite sequencing of the GAPDH and PSME1 promoters in the sorted populations revealed that DNA methylation levels were very similar in both low expressing and high expressing cells (Fig. 6, E to G). This further supports our observation that induced DNA methylation of gene promoters is frequently not sufficient to repress transcription.

To further investigate the possibility that there was a subpopulation of DNA molecules that were not methylated by ZF-D3A, we analyzed the distribution of methylation in single DNA molecules, focussing on CpG-dense WGBS reads ( $\geq 10 \mathrm{CpG}$ context cytosines) from ZFD3A + dox cells that aligned to robustly methylated DMRs (DMR mean methylation level [mCG/CG] of 0.4-0.6 in ZF-D3A +dox and <0.1 in MCF7-control). Of 16,159 reads analyzed from ZF-D3A +dox cells, only $20 \%$ had a low fraction of methylated cytosines (mCG/CG $<0.15$, Fig. $6 \mathrm{H}$ ). In contrast, $80 \%$ of reads were methylated modestly to completely (mCG/CG $\geq 0.15$ ), with $67 \%$ of 
reads exhibiting a robust gain of methylation ( $\mathrm{mCG} / \mathrm{CG} \geq 0.4$, Fig. $6 \mathrm{H}$, blue line). The genomic coordinates to which each read aligned were used to calculate the average methylation in ZF-D3A +dox cells for each read interval (Fig. $6 \mathrm{H}$, red line). While there is a broader distribution of single DNA molecule methylation levels than the selected average range, only a small subset of DNA molecules escape methylation by ZF-D3A, with most being methylated at moderate to high levels. Thus, the inability of ZF-D3A to repress gene expression at a large number of promoters appears to be due to the inability of DNA methylation on its own to induce transcriptional silencing.

Discussion. DNA methylation is commonly considered a stable and repressive modification, and targeted approaches to manipulate methylation states are being explored for both research and potential clinical applications (25). However, very little is known about whether DNA methylation can generally function as a primary instructive biochemical signal for transcriptional silencing of nearby genes and the stability of altered DNA methylation states when induced in the genome. Here we show that the simultaneous methylation of thousands of promoters in the human genome frequently resulted in no detectable repression of gene expression. Induced DNA methylation had very little, if any, effect upon the association of initiated RNA polymerase II or H3K4me3 with DNA, demonstrating that DNA methylation on its own is not sufficient to reconfigure DNA into a stable heterochromatinized state. Finally, forced DNA methylation is rapidly lost at nearly all promoters in the absence of the artificial methyltransferase, likely through TET-mediated demethylation.

It is not entirely clear how the CpG-rich regions associated with transcriptional start sites establish and retain their unmethylated state in a genome that is almost entirely methylated in the CpG context $(5,51)$. It has been proposed that de novo DNA methyltransferases are 
excluded from these regions $(41,52)$, however this cannot be the only process, because aberrant methylation deposited in $\mathrm{CpG}$ islands would require a proofreading mechanism to prevent the entire genome from drifting towards a fully methylated state. Our observations of induced DNA methylation being actively removed from gene promoters and increased levels of 5-hydroxymethylcytosine in forcibly methylated areas support a model whereby CpG islands are protected from DNA methylation by a TET-mediated surveillance process $(53,54)$. This is consistent with the observation that the CxxC domains of the TET1 and TET3 proteins specifically bind to $\mathrm{CpG}$ dinucleotides with a slight preference for the unmethylated state (55-57). Furthermore, while ZF-D3A induced large increases in DNA methylation, it did not fully methylate entire promoter regions. The broad distribution of methylation states in individual reads may reflect simultaneous catalysis of methylation by ZF-D3A and demethylation by TET proteins.

Importantly, artificially induced DNA methylation is frequently insufficient for transcriptional repression, even at genes that accumulate high levels of promoter DNA methylation. While DNA methylation is clearly an important modification, there is very little direct evidence that, on its own, it is sufficient to block transcription or force DNA into a heterochromatinized state. Observations that DNA methylation follows transcriptional repression during development have suggested that it acts as a reinforcing mark (58). Notably, Amabile et al. recently observed that a TALE-DNMT3A fusion protein targeting the $B 2 M$ gene had minimal effects upon transcription in transfected human cells, while simultaneous recruitment of DNMT3A, DNMT3L and KRAB domain proteins resulted in durable and long lasting silencing of the gene (30). The KRAB domain recruits several repressors including histone modifying proteins and the nucleosome remodelling complex NuRD (59). The requirement for both the KRAB domain and DNA methylation to stably repress transcription, taken together with our 
observation that DNA methylation is actively removed when deposited on promoters and the recognition that DNA methylation often follows gene silencing in development, suggests that active chromatin is protected against DNA methylation in part by the TET proteins, and that more extensive changes to multiple DNA and histone modifications may be required simultaneously to affect changes in chromatin structure and gene expression.

This work constitutes the first broad assessment of the repressive capacity of promoter DNA methylation in the human genome. With routine comprehensive epigenome profiling revealing extensive differential methylation between cell types and states, it is now important to establish an extensive understanding of the causal relationships between these covalent modifications and genome regulation. While this study was performed in MCF7 cells, in the future it will be important to undertake comprehensive epigenome manipulation in a wide variety of cell types and states in order to establish the generalisability of these relationships, for example in pluripotent and distinct differentiated cells. Our work demonstrates the utility of artificial epigenome editing technologies for understanding the information content of covalent modifications of the genome, and highlights potential biological barriers that need to be overcome for their use.

\section{Data access}

DNA methylation, TAB-seq, ChIP-seq, and RNA-seq data can be accessed at the Gene Expression Omnibus (GEO) under the accession number GSE102395 and viewed in the UCSC genome browser:

https://genome.ucsc.edu/cgi-bin/hgTracks?hgS doOtherUser=submit\&hgS otherUserName=et hanford\&hgS otherUserSessionName=FordEtAIBioRxiv2017. 


\section{Acknowledgements:}

We thank C. Pflüger, M. Cruickshank and M. Lewsey for critical reading of this manuscript, and Andrea Holme at the UWA Centre for Microscopy, Characterisation and Analysis and Ji Kevin Li at the Harry Perkins Institute of Medical Research Flow Cytometry Facility for performing the FACS and flow cytometry analysis. This work was funded by the Australian National Health and Medical Research Council (GNT1069830), the Australian Research Council (ARC) Centre of Excellence program in Plant Energy Biology (CE140100008), the National Institutes of Health (R01CA170370 and 1R01DA036906), the Raine Medical Research Foundation, the National Cancer Institute (P30CA014089), and the National Human Genome Research Institute (R21HG006761). RL was supported by an ARC Future Fellowship (FT120100862), a Sylvia and Charles Viertel Senior Medical Research Fellowship, and a Howard Hughes Medical Institute International Research Scholarship. OB was supported by an Australian Research Council Discovery Early Career Researcher Award (DE140101962). AdM was supported by an EMBO Long Term Fellowship (ALTF144-2014). PB was supported by an ARC Future Fellowship (FT130101767) and by a Cancer Council Western Australia Research fellowship.

\section{Materials and Methods:}

\section{Cell culture}

The MCF7-control and ZF-D3A cell lines have been described previously (25). Cells were grown in MEM a nucleosides (Life Technologies) supplemented with $0.075 \%$ sodium bicarbonate and $10 \%$ tetracycline-free fetal bovine serum (Clonetech). Doxycycline induction was performed by adding doxycycline to a final concentration of $100 \mathrm{ng} / \mathrm{ml}$. 


\section{Propidium iodide staining}

Ten centimeter cell culture dishes with cells at $30 \%$ confluency were grown for 48 hours with or without cell cycle inhibitors and harvested by incubation in PBS with $5 \mathrm{mM}$ EDTA and centrifugation at $900 \times \mathrm{g}$ in a swinging bucket rotor. The cell pellet was loosened by vortexing and ice cold $70 \%$ ethanol was added dropwise while vortexing and then incubated on ice for 1 hour. The cells were centrifuged at $900 \times \mathrm{g}$ for 5 minutes in a swinging bucket rotor and washed twice by resuspending in PBS and centrifuging at $900 \times \mathrm{g}$ for 5 minutes. Finally, the cells were resuspended in $100 \mu \mathrm{l}$ PBS and $5 \mu \mathrm{l} 100 \mathrm{mg} / \mathrm{ml}$ RNase $\mathrm{A}$ and incubated for 5 minutes at room temperature, after which $100 \mu \mathrm{l}$ of $100 \mu \mathrm{g} / \mathrm{ml}$ propidium iodide was added and the cells were analyzed on a FACScanto.

\section{Whole Genome Bisulfite Sequencing by MethylC-seq}

Genomic DNA was extracted from cells using the Qiagen Blood and Tissue Kit (Qiagen) according to the manufacturer's instructions. $1 \mu \mathrm{g}$ of genomic DNA was spiked with $0.5 \%(\mathrm{w} / \mathrm{w})$ of unmethylated lambda phage DNA (Promega) for calculation of the bisulfite non-conversion rate, and sheared with a Covaris S2 sonicator to an average length of $200 \mathrm{bp}$. The sheared DNA was end-repaired, A-tailed and ligated to methylated Illumina TruSeq adapters and subjected to 4 cycles of PCR amplification using KAPA HiFi Uracil+ DNA polymerase (KAPA Biosystems). Single-end 100 cycle sequencing was performed on an Illumina HiSeq 1500. Reads were mapped to the human genome (hg19) with the Bowtie alignment algorithm (60) as previously reported (61).

\section{TET-assisted bisulfite sequencing (TAB-seq)}


Genomic DNA was isolated as described for MethylC-seq. TAB-seq libraries were generated using the 5hmC TAB-seq kit (WiseGene) according to the manufacturer's instructions. 5-hydroxymethylated pUC19 DNA (WiseGene) was used to estimate the protection of 5hmC by $\beta$-glucosyltransferase, and unmethylated lambda phage DNA was used to estimate the bisulfite non-conversion rate. Single-end 100 cycle sequencing was performed on a HiSeq1500. Reads were mapped as described for MethylC-seq.

\section{RNA-seq}

RNA was extracted from cells using the Qiagen RNeasy kit. 330 ng of total RNA was used to generate libraries using the Illumina TruSeq Stranded mRNA kit according to the manufacturer's instructions, except one-third of all reaction volumes were used and the final amplification used 10 cycles of PCR. Reads were mapped to the human genome assembly hg19 and transcriptome using TopHat2 (62). Uniquely mapped reads were assigned to genes with HTseq-count and differentially expressed genes and fold-change of expression were calculated with DESeq2 (63). Normalized read counts from DESeq2 were used to quantitate DNMT3A expression. RNA-seq data was visualized on the UCSC genome browser by normalizing to the sample with the fewest mapped reads. FPKM values were calculated with CuffDiff2 (64). For all analyses, only genes with $>20$ uniquely mapped reads were used.

\section{ChIP-seq}

Chromatin immunoprecipitation followed by massively-parallel DNA sequencing (ChIP-seq) for the HA-tag (for HA-tagged ZF-DNMT3A localization), as well as for the H3K4me3 histone modification, was performed as described previously (37). 


\section{ChIP-bisulfite-sequencing}

Two $15 \mathrm{~cm}$ plates of cells were grown and doxycycline induced for three days. Cells were washed two times with $10 \mathrm{ml}$ of PBS and crosslinked for 5 minutes in $50 \mathrm{mM} \mathrm{HEPES-KOH}, \mathrm{pH}$ 7.5, $100 \mathrm{mM} \mathrm{NaCl}, 1 \mathrm{mM}$ EDTA, $1 \%$ formaldehyde. The crosslinking reaction was quenched by the addition of glycine to a final concentration of $125 \mathrm{mM}$ and washed twice with phosphate buffered saline (PBS). All subsequent solutions were supplemented with a protease inhibitor cocktail (Sigma Cat. \# P8340). Cells were scraped off the plates with a rubber policeman in 10 $\mathrm{ml}$ of PBS and centrifuged at 3,000 rpm for 5 minutes in a swinging bucket rotor. The cell pellets were resuspended in $10 \mathrm{ml}$ of $50 \mathrm{mM}$ HEPES-KOH, $\mathrm{pH}$ 7.9, $140 \mathrm{mM} \mathrm{NaCl}, 1 \mathrm{mM}$ EDTA, 10\% glycerol, $0.5 \%$ NP-40, $0.25 \%$ Triton X-100, incubated on ice for 10 minutes and centrifuged at $3,000 \mathrm{rpm}$ for 10 minutes in a swinging bucket rotor. Cell pellets were washed twice by gently adding $10 \mathrm{mM}$ Tris- $\mathrm{HCl}, \mathrm{pH} 8.1,200 \mathrm{mM} \mathrm{NaCl}, 1 \mathrm{mM}$ EDTA to the cell pellets, trying not to disturb the pellets, and centrifuged at 3,000 rpm for $5 \mathrm{~min}$. Finally the cell pellets were resuspended in $0.1 \% \mathrm{SDS}, 1 \mathrm{mM}$ EDTA and transferred to a Covaris TC12x12 tube. The chromatin was sheared using a Covaris S2 sonicator with the following settings: time 12 min, duty cycle $5 \%$, intensity 4 , cycles per burst 200 , temperature $4^{\circ} \mathrm{C}$, power mode frequency sweeping. Triton $\mathrm{X}-100$ and $\mathrm{NaCl}$ were added to a final concentration of $1 \%$ and $150 \mathrm{mM}$ respectively. The sheared chromatin was centrifuged at maximum speed in a microfuge for 15 minutes at $4^{\circ} \mathrm{C}$ and the supernatant was transferred to a new tube. $2 \mu \mathrm{l}$ of anti-H3K4me3 (Diagenode, Cat. \# C15410003) or $4 \mu$ l of anti-phospho-Ser5 RNA polymerase II antibody (Active Motif, Cat. \# 39233) was added and incubated overnight at $4^{\circ} \mathrm{C} .30 \mu$ of Protein $\mathrm{G}$ Dynabeads (Life Technologies) was added and incubated on a tube rotator for 90 minutes at $4^{\circ} \mathrm{C}$. The beads were washed twice with $20 \mathrm{mM}$ HEPES-KOH, pH 7.9, 0.1\% SDS, $150 \mathrm{mM}$ $\mathrm{NaCl}, 1 \%$ Triton X-100 2 mM EDTA, twice with 20 mM HEPES-KOH, pH 7.9, 0.1\% SDS, 500 
mM NaCl, 1\% Triton X-100 2 mM EDTA, once with 100 mM Tris-HCl pH 7.5, 0.5 M LiCl, 1\% NP-40, 1\% sodium deoxycholate, and once with $10 \mathrm{mM}$ Tris- $\mathrm{HCl}, \mathrm{pH} 8.0,1 \mathrm{mM}$ EDTA. The DNA was eluted twice by incubating for 30 minutes in $25 \mu \mathrm{l}$ of $20 \mathrm{mM} \mathrm{HEPES-KOH,} \mathrm{pH} 7.9,1$ $\mathrm{mM}$ EDTA, $0.5 \%$ SDS, $0.5 \mathrm{mg} / \mathrm{ml}$ Proteinase $\mathrm{K}$. To the $50 \mu \mathrm{l}$ of eluted DNA, $3 \mu \mathrm{l}$ of $3 \mathrm{M}$ sodium acetate, $\mathrm{pH} 5.3$ and $0.5 \mu \mathrm{l} 30 \mathrm{mg} / \mathrm{ml}$ RNase A was added and incubated overnight at $65^{\circ} \mathrm{C}$ in a hybridization oven. $1.5 \mu \mathrm{l}$ of $20 \mathrm{mg} / \mathrm{ml}$ proteinase $\mathrm{K}$ was added and incubated for 1 hour at $50^{\circ} \mathrm{C}$ and the DNA was purified with 2 volumes of SPRI beads and eluted in $20 \mu \mathrm{l}$ Tris- $\mathrm{HCl}, \mathrm{pH} 8.0$, $0.1 \mathrm{mM}$ EDTA. Libraries were made with the Accel-NGS Methyl-Seq DNA Library Kit (Swift Biosciences) according to the manufacturer's instructions. Reads were aligned and DNA methylation sites were identified as described for MethylC-seq above, except after adapter trimming $10 \mathrm{nt}$ were hard cropped off the 3 ' end of the read.

\section{RNA fluorescence-in-situ-hybridization and FACS sorting}

Cells were labeled with fluorescent probes to GAPDH mRNA or PSME1 mRNA using the PrimeFlow RNA kit (eBiosciences) according to the manufacturer's instructions. Cells were sorted into high and low expression populations on a FACS Aria2 by the Harry Perkins Cell Sorting Facility. The sorted cell populations were aliquoted into two tubes for RNA and DNA extraction.

\section{RNA isolation and quantitation from FACS-sorted cells}

RNA was extracted using the Qiagen RNeasy FFPE kit according the manufacturer's instructions. Exon spanning primers were designed to the GAPDH and RPL13A as an internal control. RNA was reverse transcribed with gene specific primers using SuperScript II (Life Technologies) and qPCR was performed on an LC480 thermocycler using KAPA SYBR FAST 
DNA qPCR Master Mix (Kapa Biosystems). For the PSME1 high and low expressing population, the RNA abundance was quantitated by RNA-seq. Ribosomal RNA was depleted from the sample using the RiboCop rRNA Depletion Kit (Lexogen) and libraries were generated with the TruSeq Stranded mRNA Kit (Illumina). The libraries were sequenced on an Illumina HiSeq 1500 with single-end 100 cycle sequencing. The reads were adapter and quality trimmed with cutadapt (65) and transcripts per million were calculated using Kallisto (66).

\section{Targeted Bisulfite-PCR amplicon sequencing}

DNA was extracted from FACS sorted cells and bisulfite converted with the EZ DNA Methylation-Direct Kit (Zymo Research). PCR amplicons to the GAPDH and PSME1 promoters were designed with methprimer and genomic DNA was amplified with 40 cycles of PCR using EpiMark Hot Start Taq DNA Polymerase (New England Biolabs). PCR reactions were pooled and purified with a homemade version of AMPureXP beads. $1 \mu \mathrm{g}$ of pooled PCR products in $14.5 \mu \mathrm{l}$ were phosphorylated by adding $15 \mu \mathrm{l}$ 2X Quick Ligase Buffer (New England Biolabs) and $0.5 \mu \mathrm{l}$ T4 polynucleotide kinase (New England Biolabs) and incubating at $37^{\circ} \mathrm{C}$ for 30 minutes. Illumina TruSeq adapters synthesized by IDT and annealed by heating to $99^{\circ} \mathrm{C}$ and slowly cooling to $20^{\circ} \mathrm{C}$ were ligated to the phosphorylated PCR products by adding $3.75 \mu \mathrm{l} 10 \mu \mathrm{M}$ annealed TruSeq adapters, $10 \mu \mathrm{l} 2 \mathrm{X}$ Quick Ligase Buffer (New England Biolabs) and $6 \mu \mathrm{l}$ water. The ligation reactions were incubated at $25^{\circ} \mathrm{C}$ for 20 minutes and stopped by adding $2 \mu \mathrm{l} 0.5 \mathrm{M}$ EDTA. The DNA was purified by adding $20.8 \mu \mathrm{l}$ (0.4 volumes) of SPRI beads. The libraries were subjected to single-end 300 cycle sequencing on the Illumina MiSeq. The reads were adapter trimmed with cutadapt and aligned to the human genome (hg19) with BS-Seeker2 (67) and bowtie2 (68). Methylation was called using bs-seeker2. 


\section{DNA methylation data analysis}

DMRs between MCF7-control cells and ZF-D3A +dox cells were called using the software package DSS (69). DSS was run with a low p-value cutoff to obtain the DMR boundaries with the following parameters: smoothing=TRUE, smoothing.span=500, delta=0.1, p.threshold=0.05, $\min C G=4$, dis.merge $=1000$, minlen=100, pct.sig=0. To obtain a more stringent set of DMRs, DSS was run a second time with the same parameters, except the p-value threshold was decreased to 0.005 . DMRs from the less stringent set that were also found in the more stringent set were used as the final set of DMRs for subsequent analyses.

UMRs were identified by combining the data sets from MCF7-control, MCF7-control/doxycycline withdrawn and ZF-D3A no-dox cells and were called using the software package methylSeekR (39) with the FDR cutoff set to 0.05. To filter UMRs that were called in large hypomethylated regions, UMRs that were within $40 \mathrm{~kb}$ were merged into single genomic intervals. The resulting set of genomic intervals were filtered for regions $>20 \mathrm{~kb}$ and had an average methylation of $m C G / C G<0.3$. UMRs form the original set that did not overlap with the UMRs from large unmethylated regions were used for further analyses.

The weighted DNA methylation level in DMRs and UMRs were calculated by dividing the sum of C base calls by the sum of $C+T$ base calls at all $C G$ dinucleotide positions in the reference genome in the interval. Methylation heatmaps were made by dividing DMRs into 100 bp bins and calculating sum of $\mathrm{C}$ base calls in the genomic interval by the sum of $\mathrm{C}+\mathrm{T}$ base calls in each bin. The resulting matrix was plotted with $\mathrm{MeV}$ (70). Smooth scatter plots were made with the smooth.scatter $\mathrm{R}$ function. All other plots were made with ggplot2 in $\mathrm{R}$. Replicate 
methylomes were compared by selecting DMRs that had $\geq 20$ base calls in all samples and plotting the resulting heatmap with the $\mathrm{R}$ function p.heatmap using the default parameters.

UMRs were assigned to genes by calculating the distance of the UMRs to the nearest transcriptional start site annotated by UCSC (71) with the closestBed function of the BEDTools software package (72). UMRs that fell within $2 \mathrm{~kb}$ of a transcriptional start site were assigned to the respective gene. Genes with $\leq 20$ mapped RNA-seq reads were excluded from the analysis.

Intersection of DMRs and UMRs was performed using the pybedtools (73) functions venn_gchart and venn_mpl. UMRs with multiple intersections with DMRs were counted multiple times. To compare the methylation levels in UMRs with the retention of H3K4me3, UMRs were filtered for those that contained $>100 \mathrm{mC}$ base calls and $>100 \mathrm{H} 3 \mathrm{~K} 4 \mathrm{me} 3 \mathrm{ChIP}$-seq reads mapped to the UMR.

The analysis of single WGBS reads (Fig. 6H) was performed by sub-selecting DMRs with a $\Delta \mathrm{mCG}$ between 0.4 and 0.6 , a $\mathrm{mCG}$ level of $<0.1$ in MCF7-control cells, and $\geq 50$ mapped reads. Reads mapped to DMRs that extended beyond the DMR border were trimmed to the DMR interval. The resulting reads mapped to DMRs were sub-selected for reads with $\geq 10$ cytosines in the CpG base context and for intervals that had average methylation levels between 0.4 and 0.6 in ZF-D3A +dox cells. The number of $\mathrm{C}$ and $\mathrm{T}$ base calls in each read was calculated in Python and plotted with ggplot2 in R.

\section{ChIP-seq and ChIP-bisulfite-sequencing data analysis}


For ChIP-seq, reads were mapped with the bowtie software package (60) and non-uniquely mapped reads were discarded. For ChIP-bisulfite-seq, reads were mapped and methylation was called as described for MethylC-seq. Peaks were called using MACS1.4 (74). H3K4me3 peaks from ZF-D3A no-dox and ZF-D3A +dox samples were combined and overlapping peaks were merged to the outer boundaries of each peak. Heatmaps were generated by dividing DMRs into bins of $50 \mathrm{bp}$ and counting the reads in each bin. The resulting matrices were plotted with $\mathrm{MeV}$ (70). ChIP-seq reads for H3K4me1 and H3K27ac in MCF-7 cells were obtained from the GEO database (GSE38447) (75).

H3K4me3 ChIP-seq data sets for ZF-D3A +dox and ZF-D3A no-dox cells were normalized by identifying common peaks between the two samples. Peak intervals with an average mC level of $<0.2$ were sub-selected and the number of reads mapped to $\pm 50 \mathrm{bp}$ of the peak center was used as the normalization factor. Normalized mapped reads counts in H3K4me3 read ZF-D3A no-dox and ZF-D3A +dox cells was measured across an interval $\pm 2.5 \mathrm{~kb}$ of the center of DMRs. The resulting intervals with more than 2,000 reads summed from both samples $(n=2,735)$ were used to compare H3K4me3 occupancy between ZF-D3A no-dox and ZF-D3A +dox cells.

Heatmaps of $\mathrm{H} 3 \mathrm{~K} 4 \mathrm{me} 3$ read density were made using the mapBed function of BEDtools and in $\mathrm{R}$ using the p.heatmap function. H3K4me3 reads $\pm 100 \mathrm{bp}$ of the center of DMRs were calculated with the mapBed function of BEDtools and plotted with ggplot2 in R. H3K4me3 reads mapped to UMRs were also calculated with the mapBed function of BEDtools. UMRs with >100 mapped H3K4me3 ChIP-seq reads and >100 cytosine base calls at cytosines were plotted with ggplot2 in R. 


\section{References:}

1. D. Schübeler, Function and information content of DNA methylation. Nature. 517, 321-326 (2015).

2. R. Lister et al., Human DNA methylomes at base resolution show widespread epigenomic differences. Nature. 462, 315-322 (2009).

3. M. B. Stadler et al., DNA-binding factors shape the mouse methylome at distal regulatory regions. Nature. 480, 490-495 (2011).

4. J. Boyes, A. Bird, Repression of genes by DNA methylation depends on CpG density and promoter strength: evidence for involvement of a methyl-CpG binding protein. EMBO J. 11, 327-333 (1992).

5. M. Weber et al., Distribution, silencing potential and evolutionary impact of promoter DNA methylation in the human genome. Nat. Genet. 39, 457-466 (2007).

6. L. Jackson-Grusby et al., Loss of genomic methylation causes p53-dependent apoptosis and epigenetic deregulation. Nat. Genet. 27, 31-39 (2001).

7. X. Yang et al., Gene Reactivation by 5-Aza-2'-Deoxycytidine-Induced Demethylation Requires SRCAP-Mediated H2A.Z Insertion to Establish Nucleosome Depleted Regions. PLoS Genet. 8, e1002604 (2012).

8. I. Keshet, J. Yisraeli, H. Cedar, Effect of regional DNA methylation on gene expression. Proc. Natl. Acad. Sci. U. S. A. 82, 2560-2564 (1985).

9. E. J. Murray, F. Grosveld, Site specific demethylation in the promoter of human gamma-globin gene does not alleviate methylation mediated suppression. EMBO J. 6 , 2329-2335 (1987).

10. S. U. Kass, N. Landsberger, A. P. Wolffe, DNA methylation directs a time-dependent repression of transcription initiation. Curr. Biol. 7, 157-165 (1997).

11. O. Bogdanovic et al., Temporal uncoupling of the DNA methylome and transcriptional repression during embryogenesis. Genome Res. 21, 1313-1327 (2011).

12. S. S. Hammoud et al., Chromatin and transcription transitions of mammalian adult germline stem cells and spermatogenesis. Cell Stem Cell. 15, 239-253 (2014).

13. S. Hontelez et al., Embryonic transcription is controlled by maternally defined chromatin state. Nat. Commun. 6, 10148 (2015).

14. N. Feldman et al., G9a-mediated irreversible epigenetic inactivation of Oct-3/4 during early embryogenesis. Nat. Cell Biol. 8, 188-194 (2006).

15. L. F. Lock, N. Takagi, G. R. Martin, Methylation of the Hprt gene on the inactive X occurs 
after chromosome inactivation. Cell. 48, 39-46 (1987).

16. I. Okamoto, E. Heard, Lessons from comparative analysis of X-chromosome inactivation in mammals. Chromosome Res. 17, 659-669 (2009).

17. S. Sato, W. Yoshida, H. Soejima, K. Nakabayashi, K. Hata, Methylation dynamics of IG-DMR and Gtl2-DMR during murine embryonic and placental development. Genomics. 98, 120-127 (2011).

18. I. Keshet et al., Evidence for an instructive mechanism of de novo methylation in cancer cells. Nat. Genet. 38, 149-153 (2006).

19. D. Sproul et al., Tissue of origin determines cancer-associated $\mathrm{CpG}$ island promoter hypermethylation patterns. Genome Biol. 13, R84 (2012).

20. F. Li et al., Chimeric DNA methyltransferases target DNA methylation to specific DNA sequences and repress expression of target genes. Nucleic Acids Res. 35, 100-112 (2007).

21. A. G. Rivenbark et al., Epigenetic reprogramming of cancer cells via targeted DNA methylation. Epigenetics. 7, 350-360 (2012).

22. A. N. Siddique et al., Targeted Methylation and Gene Silencing of VEGF-A in Human Cells by Using a Designed Dnmt3a-Dnmt3L Single-Chain Fusion Protein with Increased DNA Methylation Activity. J. Mol. Biol. 425, 479-491 (2013).

23. S. Nunna, R. Reinhardt, S. Ragozin, A. Jeltsch, Targeted methylation of the epithelial cell adhesion molecule (EpCAM) promoter to silence its expression in ovarian cancer cells. PLoS One. 9, e87703 (2014).

24. G. Kungulovski et al., Targeted epigenome editing of an endogenous locus with chromatin modifiers is not stably maintained. Epigenetics Chromatin. 8, 12 (2015).

25. S. Stolzenburg et al., Stable oncogenic silencing in vivo by programmable and targeted de novo DNA methylation in breast cancer. Oncogene. 34, 5427-5435 (2015).

26. G. L. Xu, T. H. Bestor, Cytosine methylation targetted to pre-determined sequences. Nat. Genet. 17, 376-378 (1997).

27. A. Vojta et al., Repurposing the CRISPR-Cas9 system for targeted DNA methylation. Nucleic Acids Res. 44, 5615-5628 (2016).

28. D. L. Bernstein, J. E. Le Lay, E. G. Ruano, K. H. Kaestner, TALE-mediated epigenetic suppression of CDKN2A increases replication in human fibroblasts. J. Clin. Invest. 125, 1998-2006 (2015).

29. X. S. Liu et al., Editing DNA Methylation in the Mammalian Genome. Cell. 167, 233-247.e17 (2016). 
30. A. Amabile et al., Inheritable Silencing of Endogenous Genes by Hit-and-Run Targeted Epigenetic Editing. Cell. 167, 219-232.e14 (2016).

31. J. I. McDonald et al., Reprogrammable CRISPR/Cas9-based system for inducing site-specific DNA methylation. Biol. Open. 5, 866-874 (2016).

32. C.-L. Lo, S. R. Choudhury, J. Irudayaraj, F. C. Zhou, Epigenetic Editing of Ascl1 Gene in Neural Stem Cells by Optogenetics. Sci. Rep. 7, 42047 (2017).

33. L. Bintu et al., Dynamics of epigenetic regulation at the single-cell level. Science. $\mathbf{3 5 1}$, 720-724 (2016).

34. P. Bashtrykov et al., Specificity of Dnmt1 for methylation of hemimethylated CpG sites resides in its catalytic domain. Chem. Biol. 19, 572-578 (2012).

35. T. H. Bestor, J. R. Edwards, M. Boulard, Notes on the role of dynamic DNA methylation in mammalian development. Proc. Natl. Acad. Sci. U. S. A. 112, 6796-6799 (2015).

36. S. Stolzenburg et al., Targeted silencing of the oncogenic transcription factor SOX2 in breast cancer. Nucleic Acids Res. 40, 6725-6740 (2012).

37. M. R. Grimmer et al., Analysis of an artificial zinc finger epigenetic modulator: widespread binding but limited regulation. Nucleic Acids Res. 42, 10856-10868 (2014).

38. M. L. Maeder et al., Rapid "Open-Source" Engineering of Customized Zinc-Finger Nucleases for Highly Efficient Gene Modification. Mol. Cell. 31, 294-301 (2008).

39. L. Burger, D. Gaidatzis, D. Schübeler, M. B. Stadler, Identification of active regulatory regions from DNA methylation data. Nucleic Acids Res. 41, e155 (2013).

40. A. M. Deaton, A. Bird, CpG islands and the regulation of transcription. Genes Dev. 25, 1010-1022 (2011).

41. S. K. T. Ooi et al., DNMT3L connects unmethylated lysine 4 of histone H3 to de novo methylation of DNA. Nature. 448, 714-717 (2007).

42. G. C. Hon et al., Global DNA hypomethylation coupled to repressive chromatin domain formation and gene silencing in breast cancer. Genome Res. 22, 246-258 (2012).

43. A. L. Statham et al., Bisulfite sequencing of chromatin immunoprecipitated DNA (BisChIP-seq) directly informs methylation status of histone-modified DNA. Genome Res. 22, 1120-1127 (2012).

44. A. B. Brinkman et al., Sequential ChIP-bisulfite sequencing enables direct genome-scale investigation of chromatin and DNA methylation cross-talk. Genome Res. 22, 1128-1138 (2012).

45. F. M. Piccolo, A. G. Fisher, Getting rid of DNA methylation. Trends Cell Biol. 24, 136-143 
(2014).

46. S. Javanmoghadam-Kamrani, K. Keyomarsi, Synchronization of the cell cycle using lovastatin. Cell Cycle. 7, 2434-2440 (2008).

47. C. McFarlane et al., The deubiquitinating enzyme USP17 is highly expressed in tumor biopsies, is cell cycle regulated, and is required for G1-S progression. Cancer Res. 70, 3329-3339 (2010).

48. H. T. Ma, R. Y. C. Poon, Synchronization of HeLa Cells. Methods Mol. Biol. 1524, 189-201 (2017).

49. M. Tahiliani et al., Conversion of 5-methylcytosine to 5-hydroxymethylcytosine in mammalian DNA by MLL partner TET1. Science. 324, 930-935 (2009).

50. M. Yu et al., Tet-assisted bisulfite sequencing of 5-hydroxymethylcytosine. Nat. Protoc. 7, 2159-2170 (2012).

51. H. K. Long, H. W. King, R. K. Patient, D. T. Odom, R. J. Klose, Protection of CpG islands from DNA methylation is DNA-encoded and evolutionarily conserved. Nucleic Acids Res. 44, 6693-6706 (2016).

52. X. Guo et al., Structural insight into autoinhibition and histone H3-induced activation of DNMT3A. Nature. 517, 640-644 (2015).

53. K. Williams, J. Christensen, K. Helin, DNA methylation: TET proteins-guardians of CpG islands? EMBO Rep. 13, 28-35 (2012).

54. L. Kong et al., A primary role of TET proteins in establishment and maintenance of De Novo bivalency at CpG islands. Nucleic Acids Res. 44, 8682-8692 (2016).

55. H. Zhang et al., TET1 is a DNA-binding protein that modulates DNA methylation and gene transcription via hydroxylation of 5-methylcytosine. Cell Res. 20, 1390-1393 (2010).

56. Y. Xu et al., Genome-wide regulation of $5 \mathrm{hmC}, 5 \mathrm{mC}$, and gene expression by Tet1 hydroxylase in mouse embryonic stem cells. Mol. Cell. 42, 451-464 (2011).

57. Y. Xu et al., Tet3 CXXC domain and dioxygenase activity cooperatively regulate key genes for Xenopus eye and neural development. Cell. 151, 1200-1213 (2012).

58. Z. D. Smith, A. Meissner, DNA methylation: roles in mammalian development. Nat. Rev. Genet. 14, 204-220 (2013).

59. A. Lupo et al., KRAB-Zinc Finger Proteins: A Repressor Family Displaying Multiple Biological Functions. Curr. Genomics. 14, 268-278 (2013).

60. B. Langmead, C. Trapnell, M. Pop, S. L. Salzberg, Ultrafast and memory-efficient alignment of short DNA sequences to the human genome. Genome Biol. 10, R25 (2009). 
61. R. Lister et al., Hotspots of aberrant epigenomic reprogramming in human induced pluripotent stem cells. Nature. 471, 68-73 (2011).

62. D. Kim et al., TopHat2: accurate alignment of transcriptomes in the presence of insertions, deletions and gene fusions. Genome Biol. 14, R36 (2013).

63. M. I. Love, W. Huber, S. Anders, Moderated estimation of fold change and dispersion for RNA-seq data with DESeq2. Genome Biol. 15, 550 (2014).

64. C. Trapnell et al., Differential analysis of gene regulation at transcript resolution with RNA-seq. Nat. Biotechnol. 31, 46-53 (2013).

65. M. Martin, Cutadapt removes adapter sequences from high-throughput sequencing reads. EMBnet.journal. 17, 10-12 (2011).

66. N. L. Bray, H. Pimentel, P. Melsted, L. Pachter, Near-optimal probabilistic RNA-seq quantification. Nat. Biotechnol. 34, 525-527 (2016).

67. W. Guo et al., BS-Seeker2: a versatile aligning pipeline for bisulfite sequencing data. BMC Genomics. 14, 774 (2013).

68. B. Langmead, S. L. Salzberg, Fast gapped-read alignment with Bowtie 2. Nat. Methods. 9, 357-359 (2012).

69. H. Feng, K. N. Conneely, H. Wu, A Bayesian hierarchical model to detect differentially methylated loci from single nucleotide resolution sequencing data. Nucleic Acids Res. 42, e69 (2014).

70. E. A. Howe, R. Sinha, D. Schlauch, J. Quackenbush, RNA-Seq analysis in MeV. Bioinformatics. 27, 3209-3210 (2011).

71. K. R. Rosenbloom et al., The UCSC Genome Browser database: 2015 update. Nucleic Acids Res. 43, D670-81 (2015).

72. A. R. Quinlan, I. M. Hall, BEDTools: a flexible suite of utilities for comparing genomic features. Bioinformatics. 26, 841-842 (2010).

73. R. K. Dale, B. S. Pedersen, A. R. Quinlan, Pybedtools: a flexible Python library for manipulating genomic datasets and annotations. Bioinformatics. 27, 3423-3424 (2011).

74. J. Feng, T. Liu, Y. Zhang, Curr. Protoc. Bioinformatics, in press.

75. S. Frietze et al., Cell type-specific binding patterns reveal that TCF7L2 can be tethered to the genome by association with GATA3. Genome Biol. 13, R52 (2012). 


\section{Ford et al. Figure 1}

bioRxiv preprint doi: https://doi.org/10.1101/170506; this version posted September 20, 2017. The copyright holder for this preprint (which was not certified by peer review) is the author/funder, who has granted bioRxiv a license to display the preprint in perpetuity. It is made available under aCC-BY-NC-ND 4.0 International license.

A

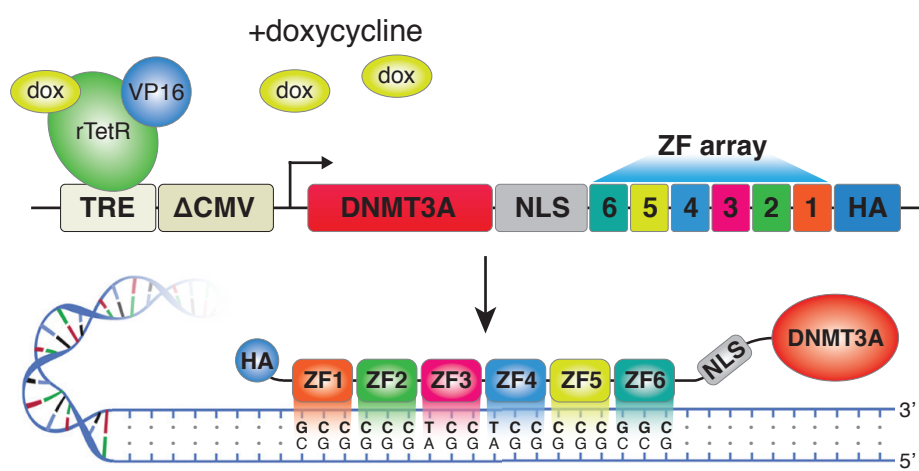

B
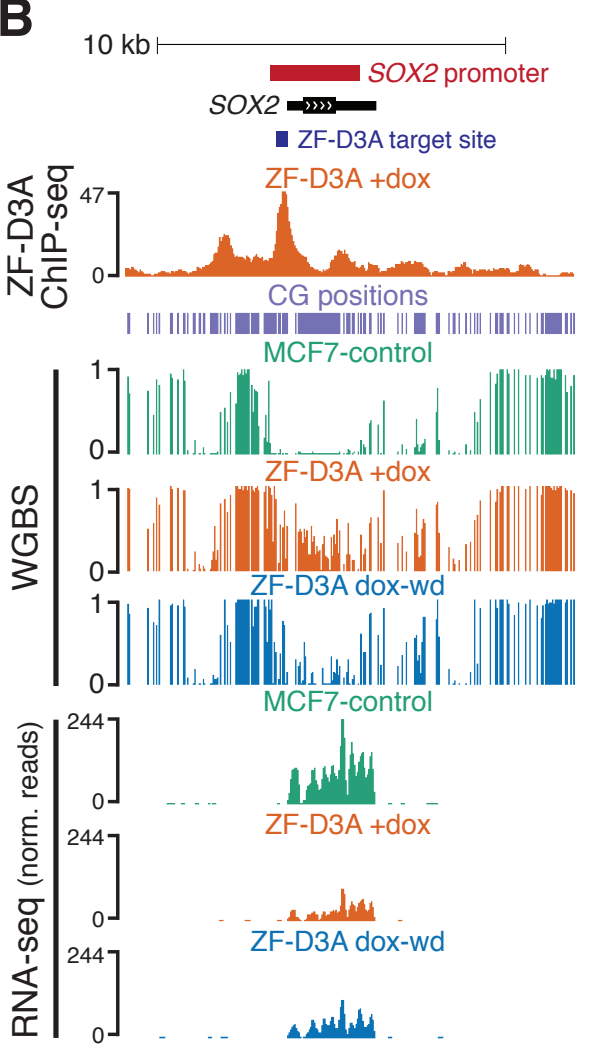
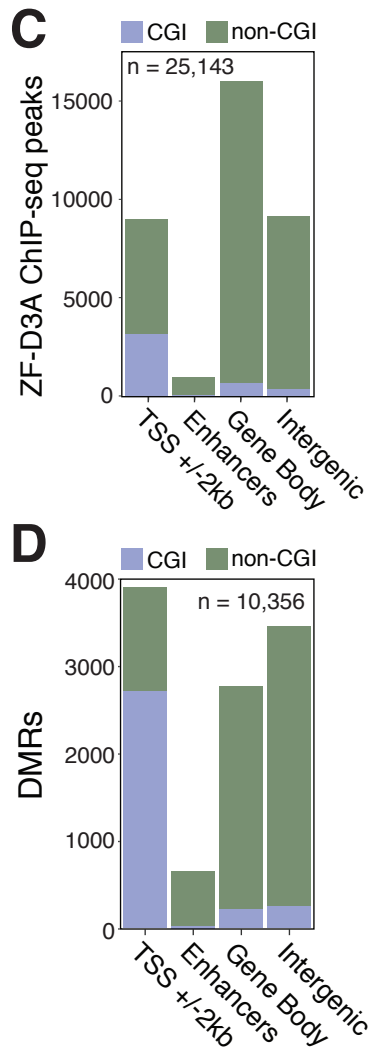

E
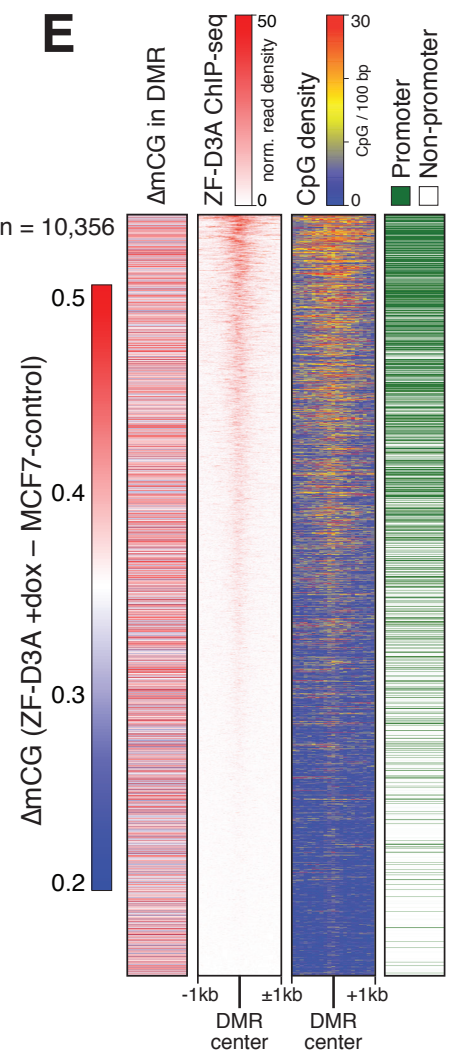

G

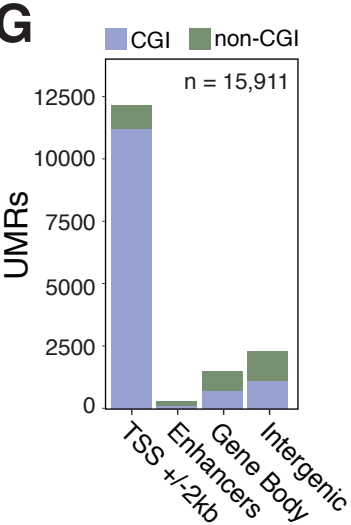

$\mathbf{F}$
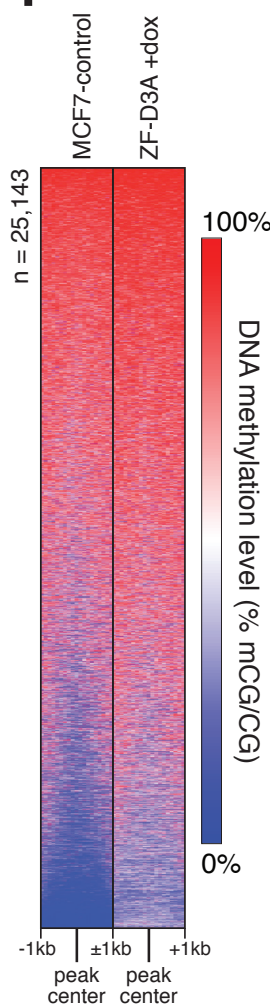

H

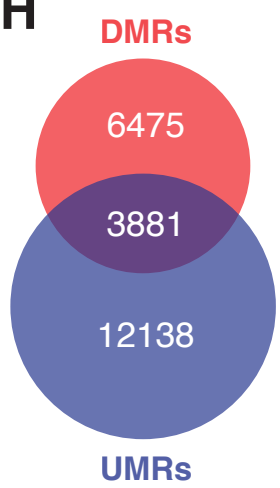

Fig. 1. Genome-wide manipulation DNA methylation with ZF-D3A. (A) Schematic representation of the ZF-D3A doxycycline inducible system. (B) Genome browser representation of the SOX2 locus. The promoter is defined as the unmethylated region spanning the SOX2 transcriptional start site in MCF7-control. Genomic distribution of (C) identified ZF-D3A binding sites, and (D) differentially methylated regions (DMRs) between MCF7-control and ZF-D3A +dox. (E) Shown for all DMRs identified between ZF-D3A +dox and MCF7-control is: $\triangle \mathrm{mCG}$ (difference in the methylation level [ratio of $\mathrm{C}$ base calls to total base calls for all CG dinucleotides in region, mCG/CG] between ZF-D3A +dox and MCF7-control), ZF-D3A ChIP-seq signal (normalized ChIP-seq read density, $\pm 1 \mathrm{~kb}$ flanking DMR center), CpG dinucleotide density (CpG/100bp, $\pm 1 \mathrm{~kb}$ flanking DMR center), and classification of each DMR as promoter or non-promoter located. (F) DNA methylation level in MCF7-control and ZF-D3A +dox cells flanking ( $\pm 1 \mathrm{~kb}, 100 \mathrm{bp}$ bins) the center of ZF-D3A ChIP-seq peaks identified in ZF-D3A +dox. (G) Genomic distribution of unmethylated regions (UMRs) in MCF7-control. (H) DMRs and UMRs with an intersection of $\geq 1 \mathrm{bp}$. 
bioRxiv preprint doi: https://doi.org/10.1101/170506; this version posted September 20, 2017. The copyright holder for this preprint (which was not certified by peer review) is the author/funder, who has granted bioRxiv a license to display the preprint in perpetuity. It is made available A under a-BY-NC-ND 4.0 International license.
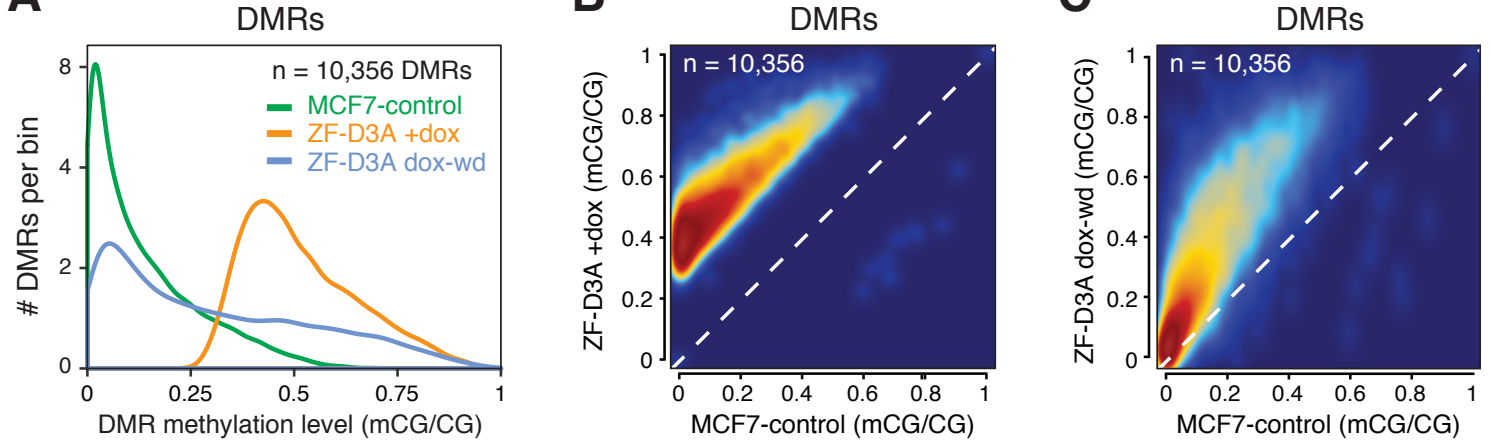

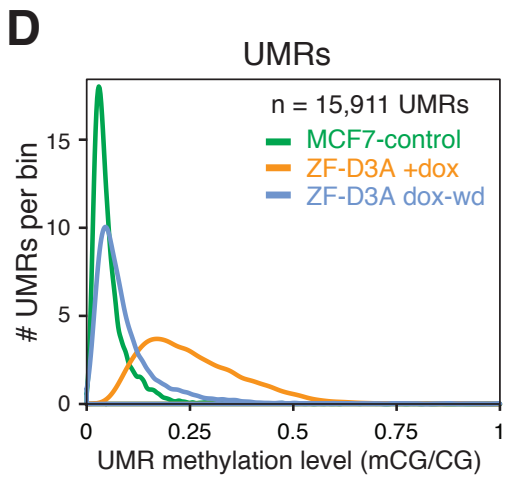

$\mathbf{E}$

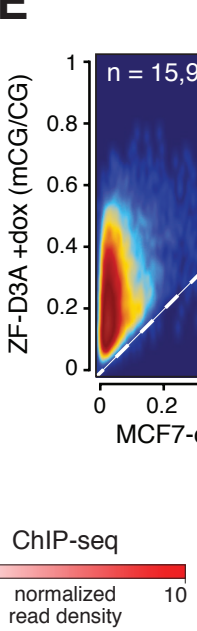

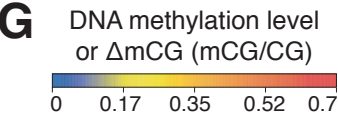
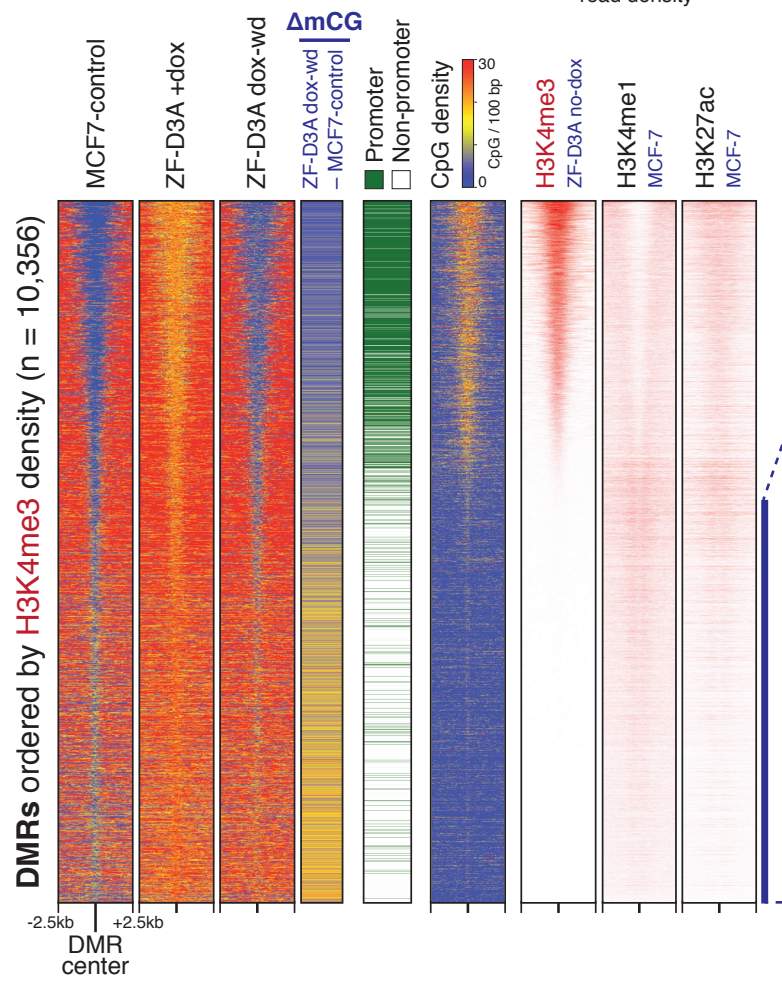

UMRs

$\mathbf{F}$

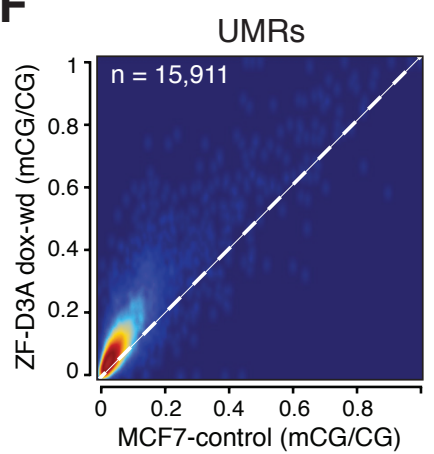

H DNA methylation level
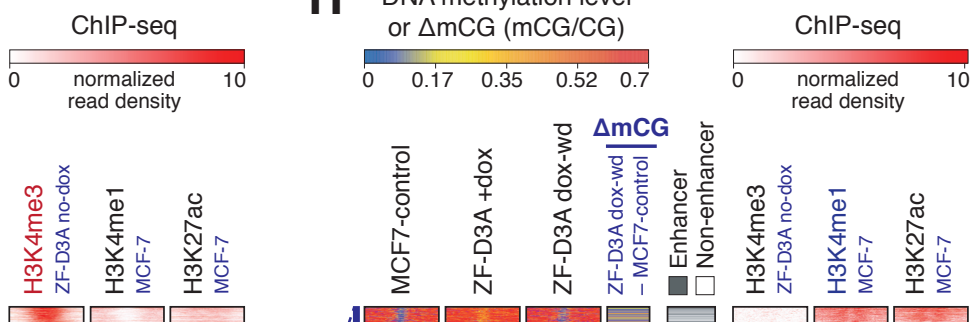
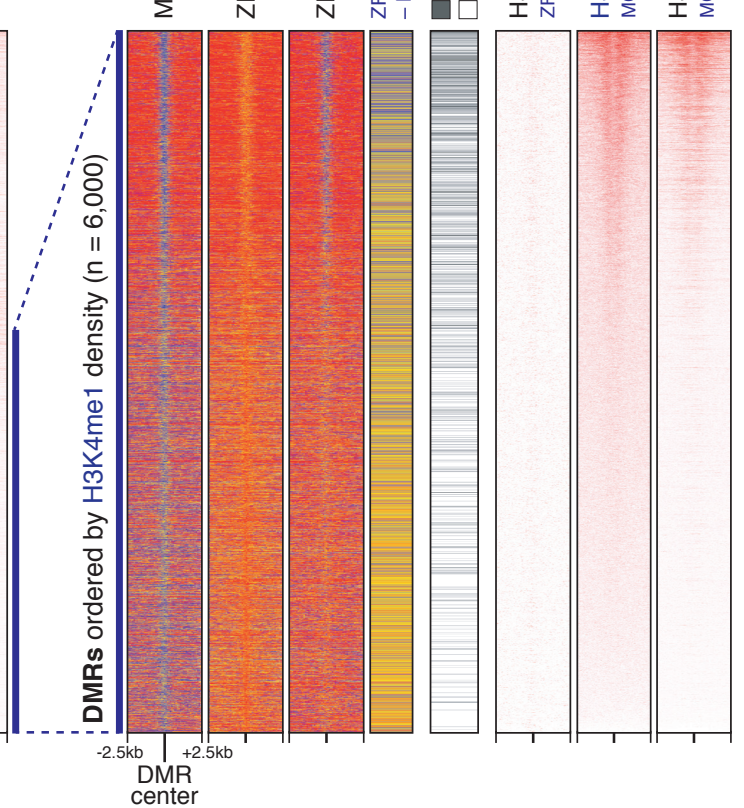

Fig. 2. Induced methylation is frequently transient and preferentially lost from $\mathrm{H} 3 \mathrm{~K} 4 \mathrm{me} 3$ marked regions. (A) Line histogram of DMR methylation levels in each sample. Kernel density estimate smoothed scatterplot comparison of DMR methylation levels in MCF7-control and (B) ZF-D3A +dox, or (C) ZF-D3A dox-wd. (D) Line histogram of UMR methylation levels in each sample. Scatterplot comparison of UMR methylation levels in MCF7-control and (E) ZF-D3A +dox, or (F) ZF-D3A dox-wd. (G) Heatmaps of DMRs (ordered by decreasing $\mathrm{H} 3 \mathrm{~K} 4 \mathrm{me} 3$ read density) showing: DNA methylation levels $( \pm 2.5$ $\mathrm{kb})$, differences $(\triangle \mathrm{mCG})$, classification as promoter or non-promoter located, $\mathrm{CpG}$ dinucleotide density $( \pm 2.5 \mathrm{~kb})$, and histone modification ChIP-seq read density $( \pm 2.5 \mathrm{~kb})$; (H) As in $(\mathrm{G})$ but for the 6,000 DMRs with the lowest $\mathrm{H} 3 \mathrm{~K} 4 \mathrm{me} 3$ levels, ordered by decreasing $\mathrm{H} 3 \mathrm{~K} 4 \mathrm{me} 1$ read density, and DMR classification as enhancer or non-enhancer in MCF7 (ENCODE). 

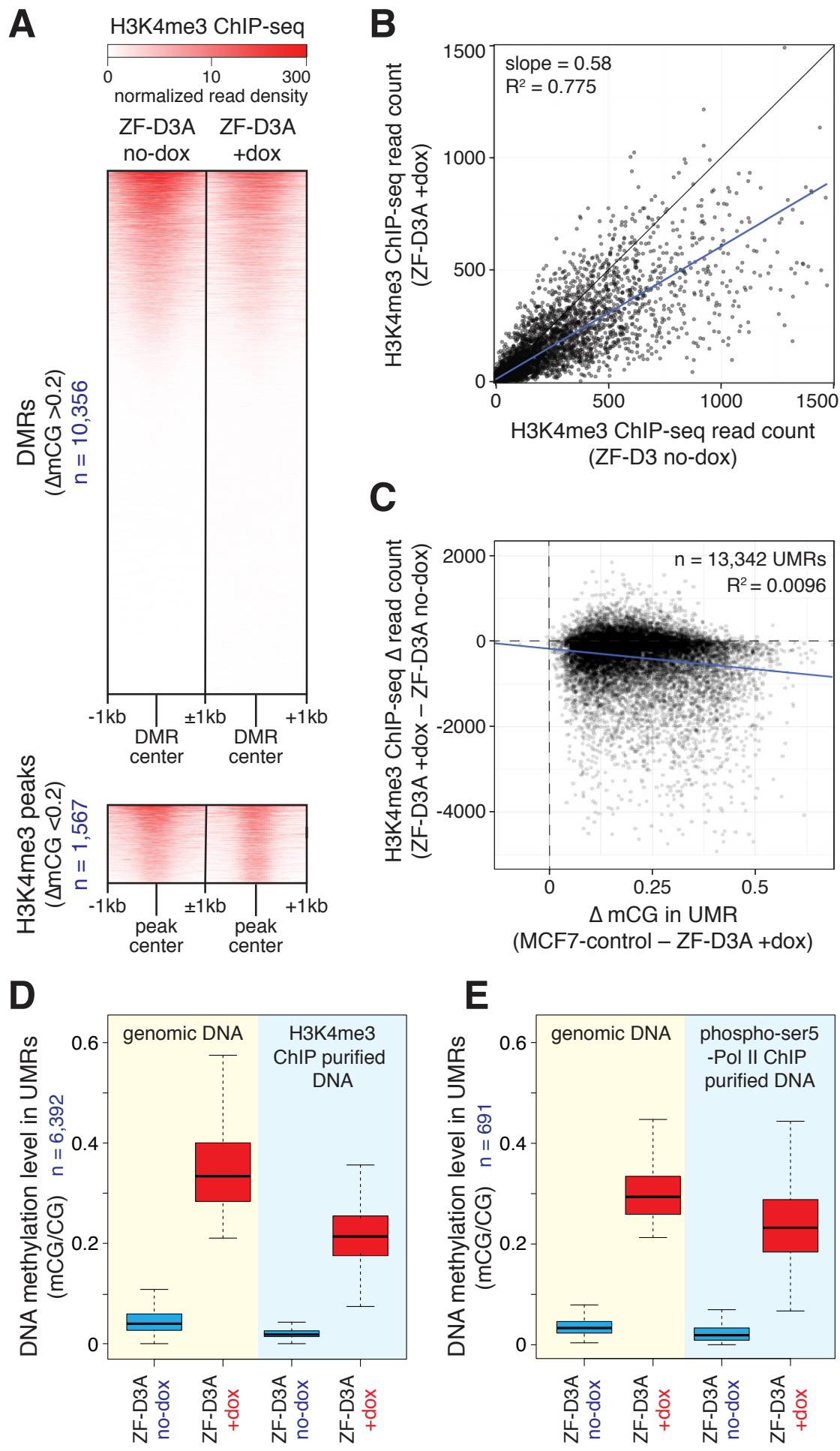

Fig. 3. DNA methylated by ZF-D3A is bound by H3K4me3 and initiated RNA polymerase II. (A) H3K4me3 ChIP-seq read density flanking ( $\pm 1 \mathrm{~kb}, 50 \mathrm{bp}$ bins) the centre of DMRs with $\triangle \mathrm{mCG}>0.2$ (top), and H3K4me3 ChIP-seq peaks with $\triangle m C G<0.2$ (bottom). (B) H3K4me3 ChIP-seq normalized read counts in DMRs with $\triangle m C G$ $>0.2$, from H3K4me3 ChIP-seq in ZF-D3A no-dox and ZF-D3A +dox cells. Black line represents equal normalized read counts in ZF-D3A no-dox and ZF-D3A +dox cells; blue line represents a linear regression of the data. (C) Comparison of UMR $\triangle \mathrm{mCG}$ and difference in H3K4me3 ChIP-seq normalized read counts between ZF-D3A no-dox and ZF-D3A +dox. Blue line represents a linear regression of the data. (D) DNA methylation levels of UMRs that intersect with H3K4me3 ChIP-seq peaks in ZF-D3A no-dox and ZF-D3A +dox cells, for genomic DNA or DNA immunoprecipitated with an anti-H3K4me3 antibody. (E) DNA methylation levels of UMRs that intersect with phospho-ser5 RNA polymerase II ChIP-seq peaks in ZF-D3A no-dox and ZF-D3A +dox cells, for genomic DNA or DNA immunoprecipitated with an anti-phospho-ser5 RNA polymerase II antibody. 
bioRxiv preprint doi: https://doi.org/10.1101/170506; this version posted September 20, 2017. The copyright holder for this preprint (which was not certified by peer review) is the author/funder, who has granted bioRxiv a license to display the preprint in perpetuity. It is made available under aCC-BY-NC-ND 4.0 International license.
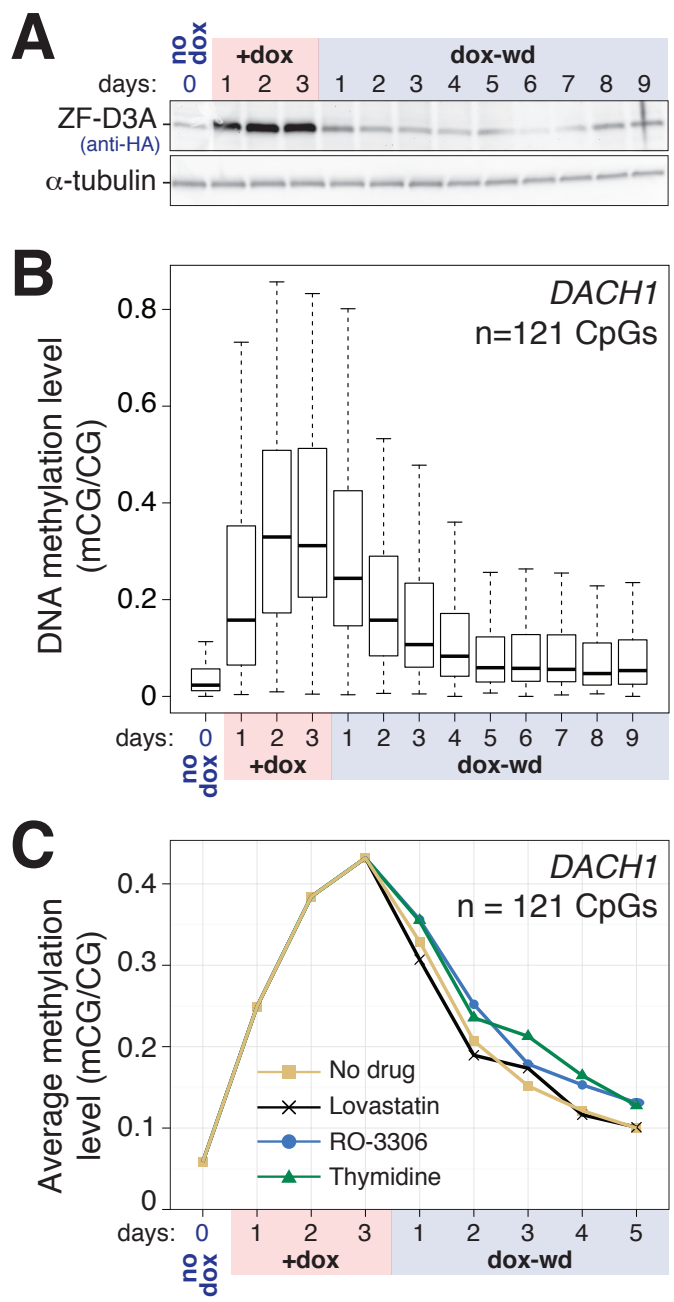

D

$$
\text { D }
$$

$\mathrm{mCG}$

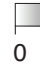

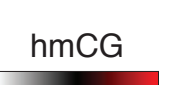
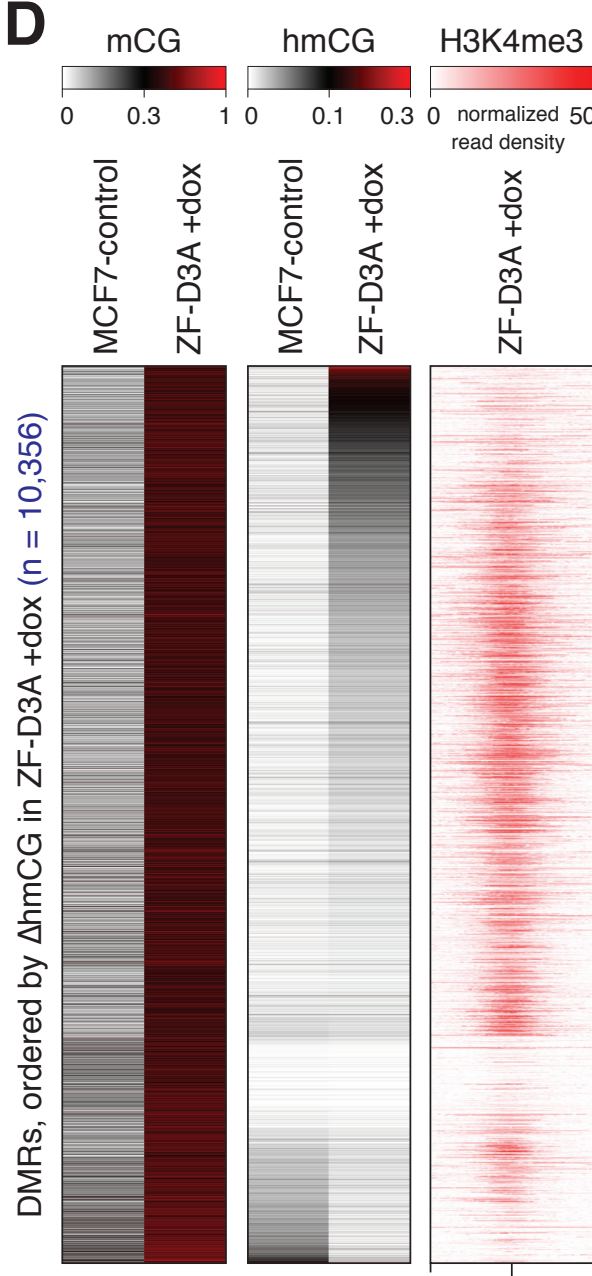
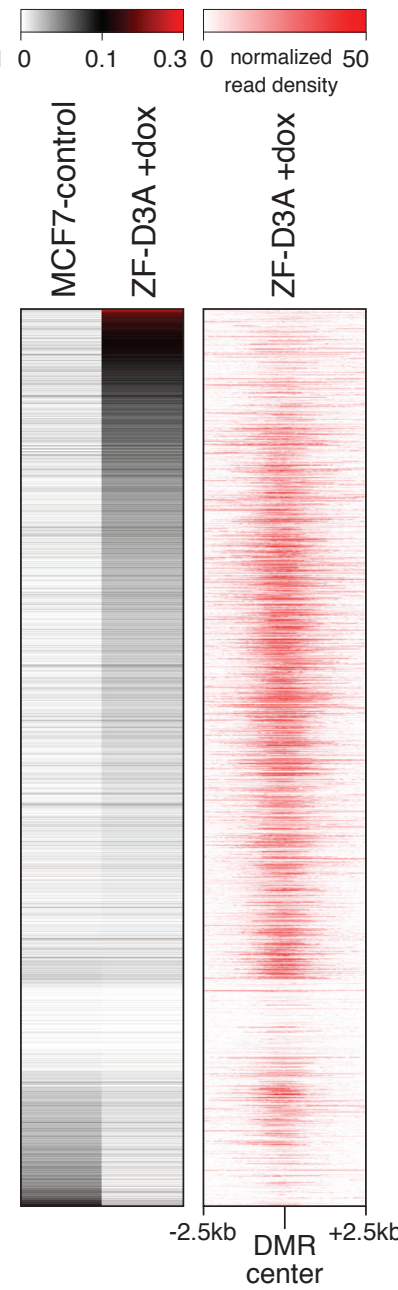

$\mathbf{E}$
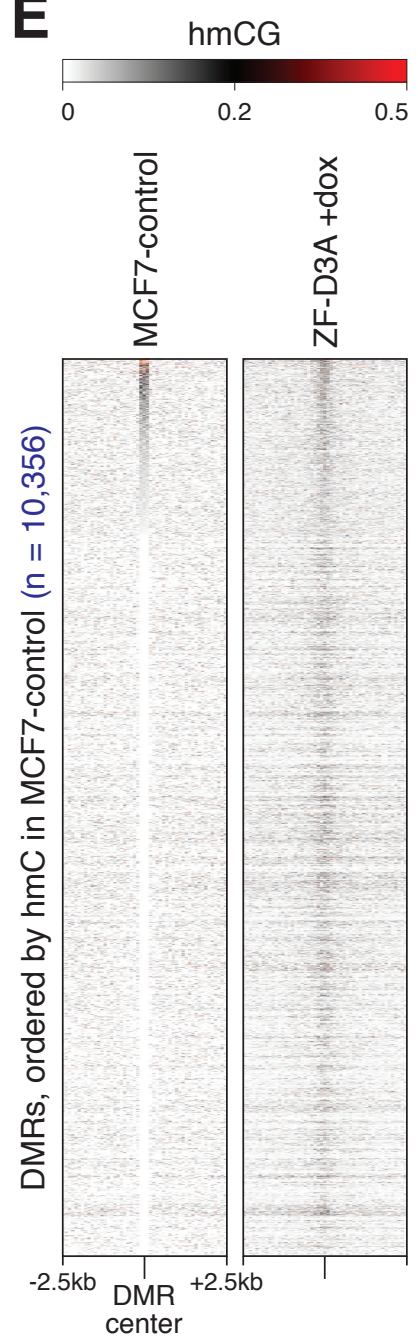

Fig. 4. DNA methylation is lost in the absence of ZF-D3A by an active process. (A) Western blot measurement of ZF-D3A protein abundance upon doxycycline induction and withdrawal. (B) Box and whisker plots of the DNA methylation levels of the $121 \mathrm{CpG}$ sites in the DACH1 promoter region throughout doxycycline induction and withdrawal. Whiskers indicate 1.5 times the interquartile range or the most extreme data point, whichever is lower. (C) Average DNA methylation level at the $121 \mathrm{CpG}$ sites in the $D A C H 1$ promoter region throughout doxycycline induction followed by doxycycline withdrawal and cell cycle inhibition by growth in doxycycline-free media containing different cell cycle inhibitors (Lovastatin, RO-3306, thymidine). (D) DMR mCG and hmCG levels in MCF7-control and ZF-D3A +dox cells, ordered by the difference in DMR hmCG level (hmCG/CG) between MCF7-control and ZF-D3A +dox cells, and heatmap representation of $\mathrm{H} 3 \mathrm{~K} 4 \mathrm{me} 3$ levels in ZF-D3A +dox cells flanking ( $\pm 2.5 \mathrm{~kb}, 50 \mathrm{bp}$ bins) the centre of the DMRs. (E) Heatmap of hmCG levels flanking ( $\pm 2.5 \mathrm{~kb}, 50 \mathrm{bp}$ bins) the centre of the DMRs, ordered by DMR hmCG level in MCF7-control cells. 
bioRxiv preprint doi: https://doi.org/10.1101/170506; this version posted September 20, 2017. The copyright holder for this preprint (which was not certified by peer review) is the author/funder, who has granted bioRxiv a license to display the preprint in perpetuity. It is made available under aCC-BY-NC-ND 4.0 International license.

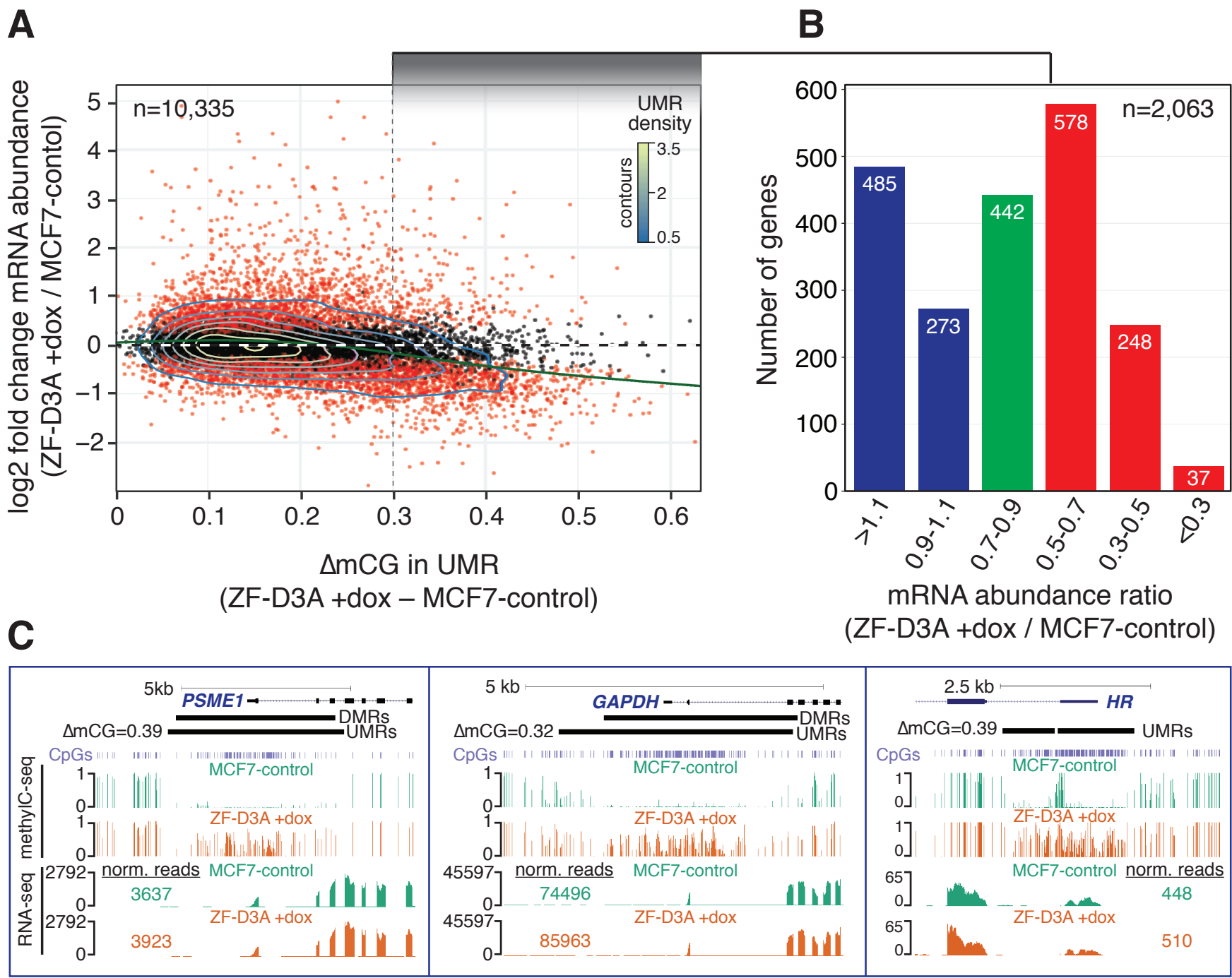

Fig. 5. Forced promoter methylation is frequently insufficient for transcriptional repression. (A) Scatter plot of the difference in UMR DNA methylation levels, versus the fold change in mRNA abundance of UMR-associated expressed genes, between MCF7-control and ZF-D3A +dox. Point color indicates the gene differential expression significance: red indicates FDR $<0.01$, black indicates FDR $>0.01$. Trend line (green) was fitted using a generalized additive model, and contour lines represent the relative density of UMRs. (B) Distribution of the ratios of mRNA levels between ZF-D3A +dox and MCF7-control, for expressed genes that have an associated UMR with a $\triangle \mathrm{mCG}>0.3$. Column color indicates the class of mRNA abundance ratios between ZF-D3A +dox and MCF7-control: blue = no decrease; green = small decrease; red = decrease. (C) Representative genes with high induction of promoter DNA methylation in ZF-D3A +dox and no reduction in mRNA abundance. 
A

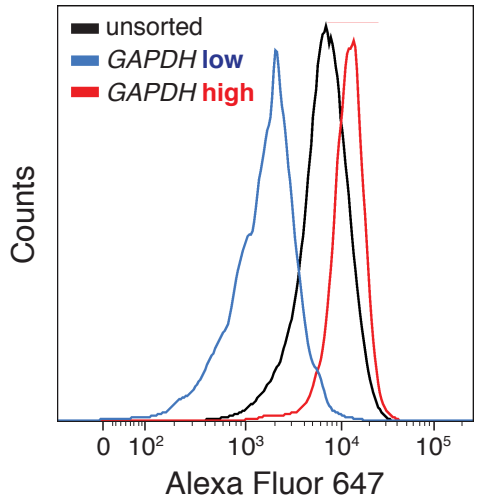

B

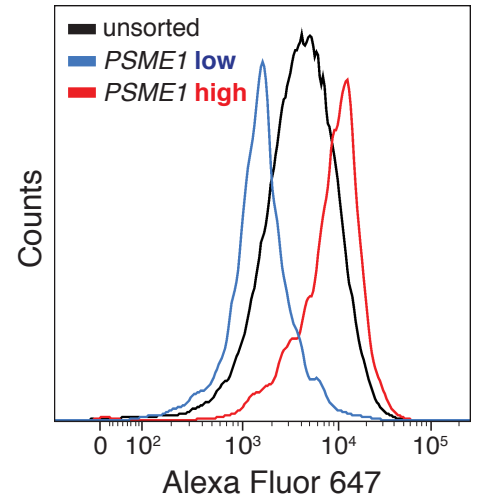

C

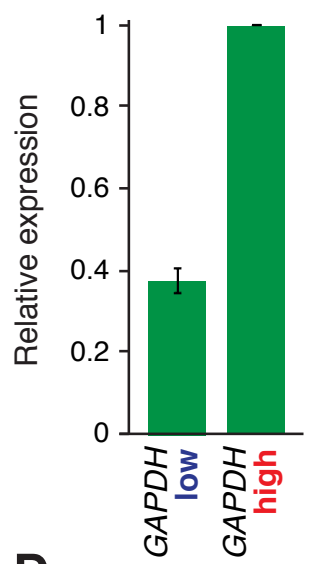

D

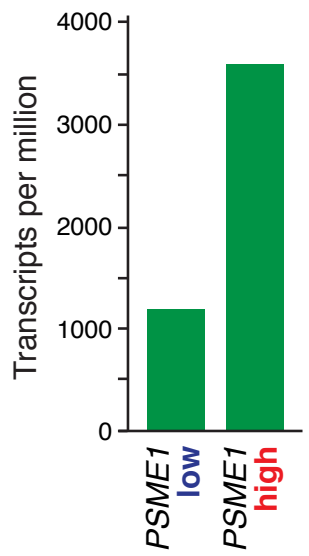

G
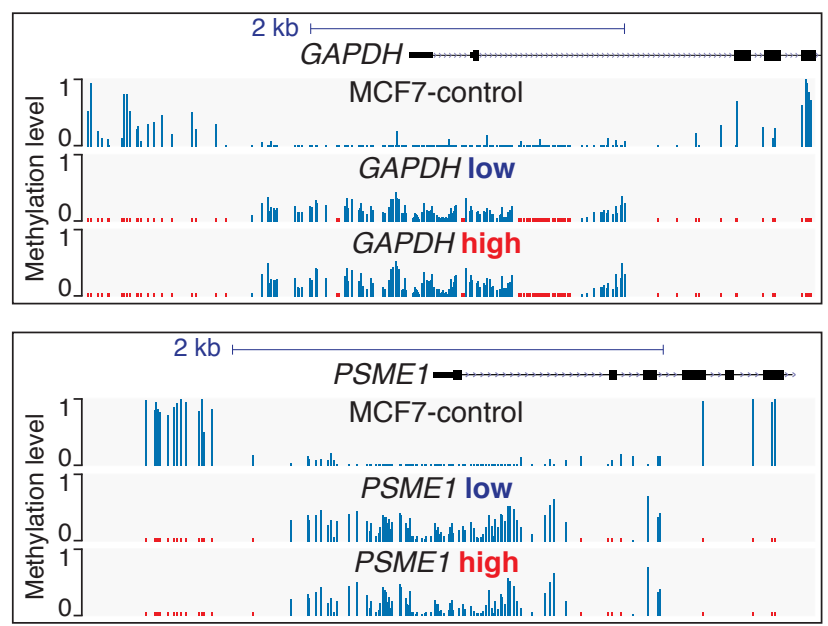

E

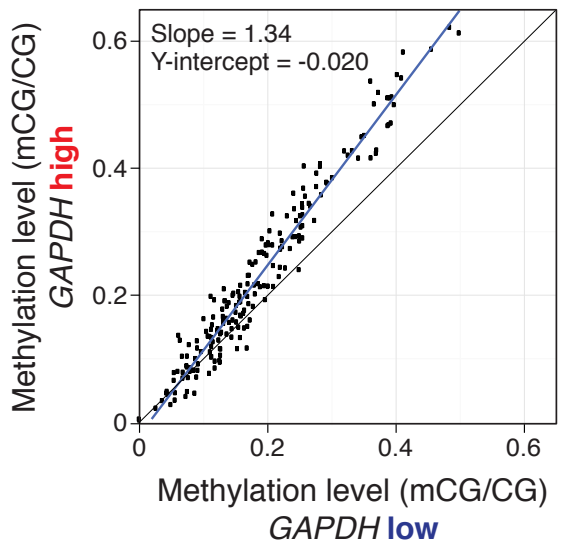

F

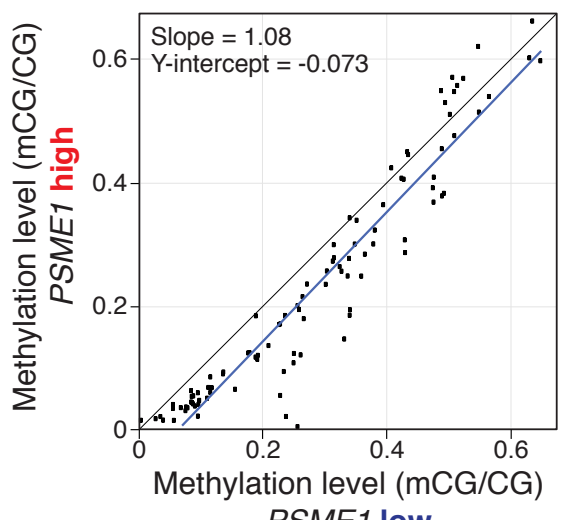

H

PSME1 low

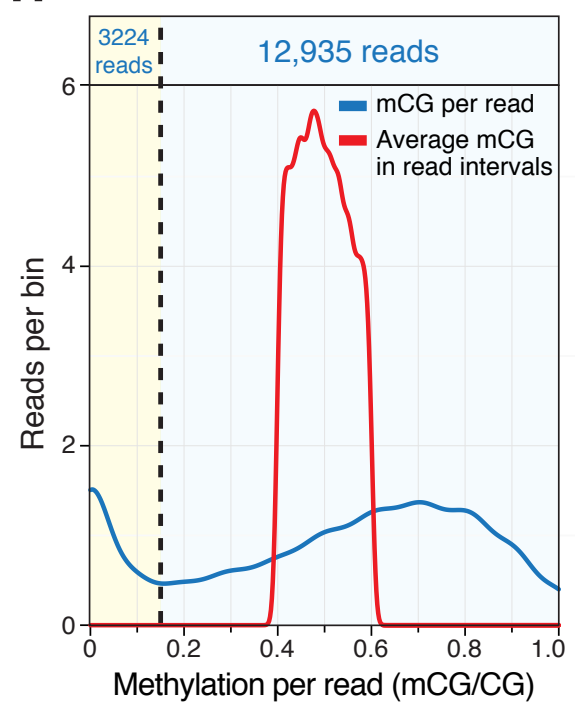

Fig. 6. Heterogeneity in gene expression between cells does not reflect differences in DNA methylation. Fluorescence distribution of cells stained with RNA-FISH probes targeting (A) GAPDH or (B) PSME1 mRNA before and after FACS. mRNA quantitation after FACS sorting of (C) GAPDH by RT-qPCR, and (D) PSME1 by RNA-seq. DNA methylation levels of single CpGs at the promoter region of (E) GAPDH, and (F) PSME1, for the low (x axis) and high (y axis) expressing sorted cell populations. (G) Genome browser representation of the GAPDH (top) and PSME1 (bottom) promoter regions showing DNA methylation in MCF7-control and low and high expressing sorted cell populations. (H) Distribution of per-read methylation levels (blue line) for selected ZF-D3A +dox WGBS reads ( $\geq 10$ cytosines in the CpG context) that align within robustly methylated DMRs (DMR mean methylation level [mCG/CG] of 0.4-0.6 in ZF-D3A +dox and <0.1 in MCF7-control), and average CG methylation levels from ZF-D3A +dox WGBS data of the DMR genomic intervals covered by the selected reads (red line). 


\section{Ford et al. Supplementary Figure 1}

bioRxiv preprint doi: https://doi.org/10.1101/170506; this version posted September 20, 2017. The copyright holder for this preprint (which was not certified by peer review) is the author/funder, who has granted bioRxiv a license to display the preprint in perpetuity. It is made available under aCC-BY-NC-ND 4.0 International license.

A DNA methylation level or $\triangle \mathrm{mCG}(\mathrm{mCG} / \mathrm{CG})$

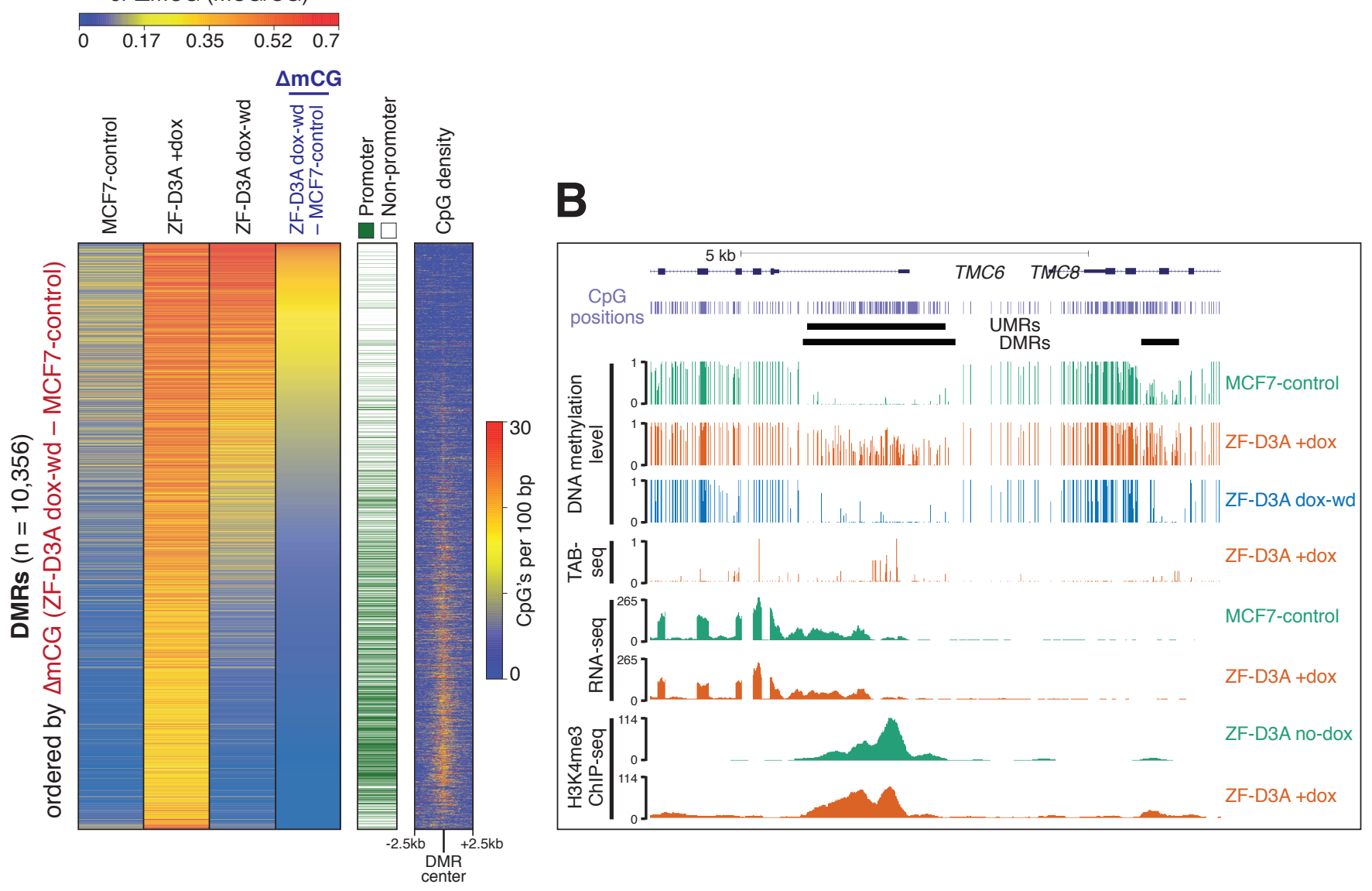

\section{Supplementary Fig. S1.}

(A) Heatmap of DNA methylation levels and differences in all DMRs $(n=10,356)$ ordered by decreasing $\triangle \mathrm{mCG}$ (ZF-D3A dox-wd - MCF7-control) in DMRs, classification of each DMR as promoter or non-promoter located, and $\mathrm{CpG}$ dinucleotide density flanking ( $\pm 2.5 \mathrm{~kb}, 100 \mathrm{bp}$ bins) the center of all DMRs. (B) Genome browser screenshots of a representative locus showing off-target DNA methylation by ZF-D3A in the TMC6 and TMC8 promoter regions. 
bioRxiv preprint doi: https://doi.org/10.1101/170506; this version posted September 20, 2017. The copyright holder for this preprint (which was not certified by peer review) is the author/funder, who has granted bioRxiv a license to display the preprint in perpetuity. It is made available under aCC-BY-NC-ND 4.0 International license.

A
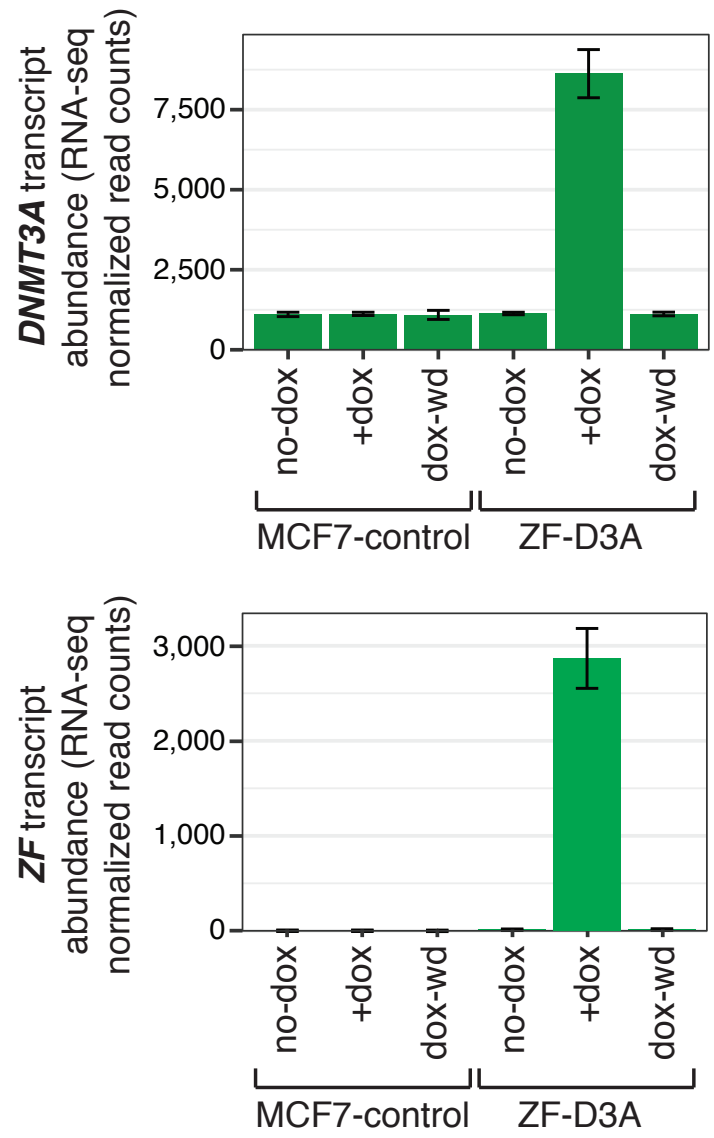

B

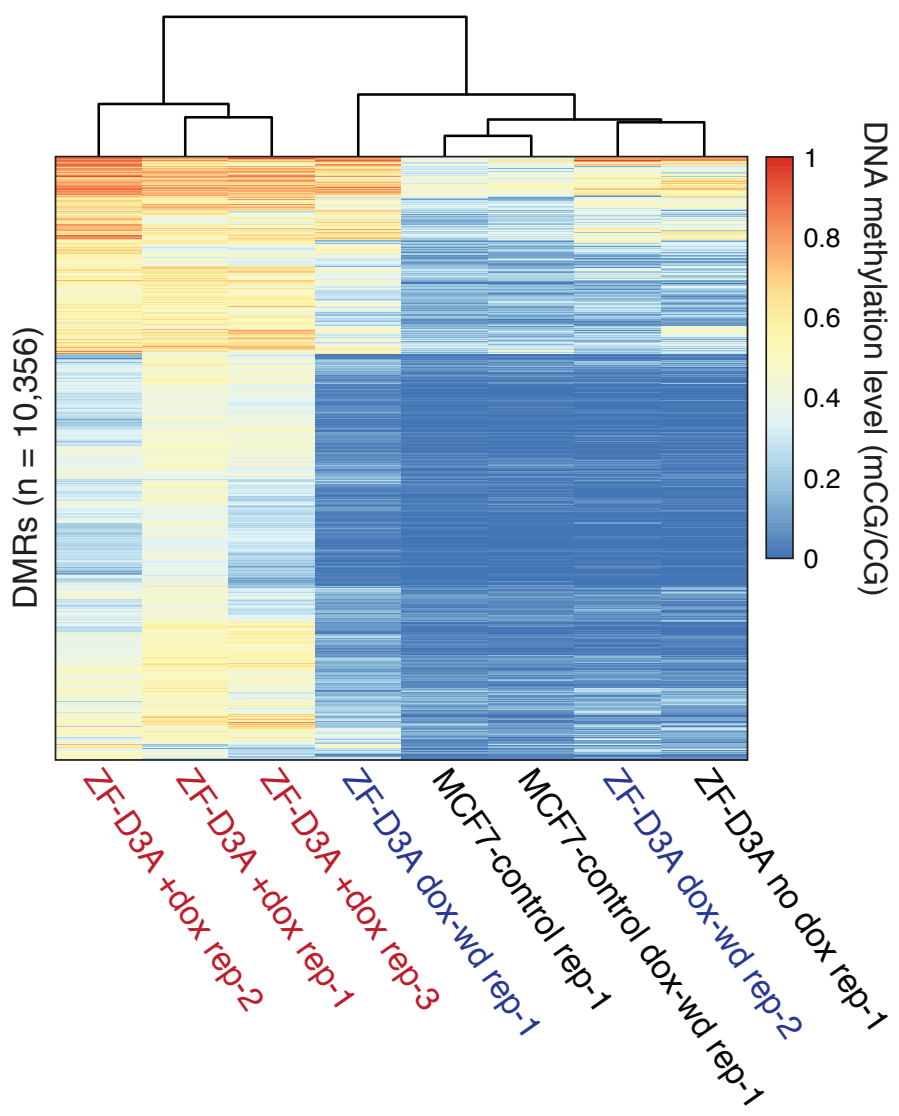

C

RNA-seq

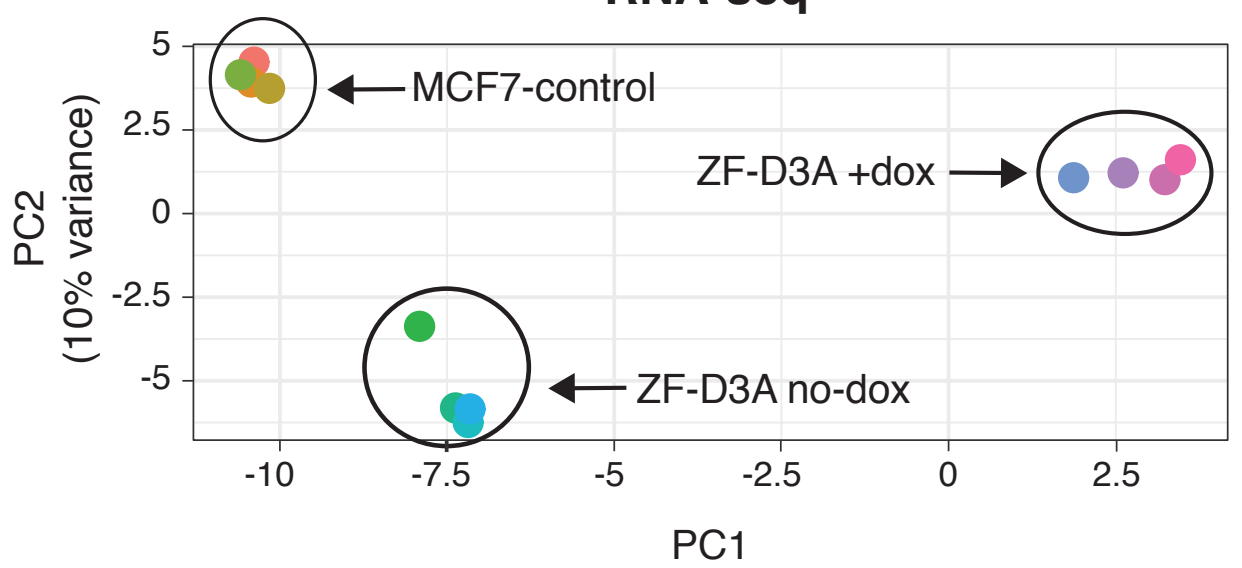

MCF7-control rep-1 MCF7-control rep-2 MCF7-control rep-3

MCF7-control rep-4

ZF-D3A no-dox rep-1

ZF-D3A no-dox rep-2

ZF-D3A no-dox rep-3

ZF-D3A no-dox rep-4

ZF-D3A +dox rep-1

ZF-D3A +dox rep-2

ZF-D3A +dox rep-3

ZF-D3A +dox rep-4

(83\% variance)

\section{Supplementary Fig. S2.}

(A) Quantitation of ZF and DNMT3A transcript abundance by RNA-seq in MCF7-control and ZF-D3A cells grown either with no doxycycline (no-dox), in the presence of doxycycline (3 days; + dox), or after doxycycline withdrawal (9 days; dox-wd). Error bars represent standard error of the mean. (B) DNA methylation levels (mCG/CG) in DMRs in all WGBS datasets. (C) PCA plot of biological replicate RNA-seq datasets. 
bioRxiv preprint doi: https://doi.org/10.1101/170506; this version posted September 20, 2017. The copyright holder for this preprint (which was not certified by peer review) is the author/funder, who has granted bioRxiv a license to display the preprint in perpetuity. It is made available under aCC-BY-NC-ND 4.0 International license.

A

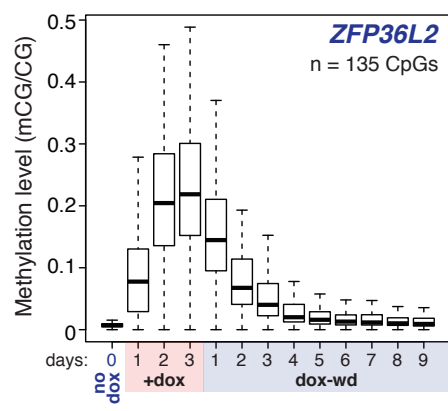

D

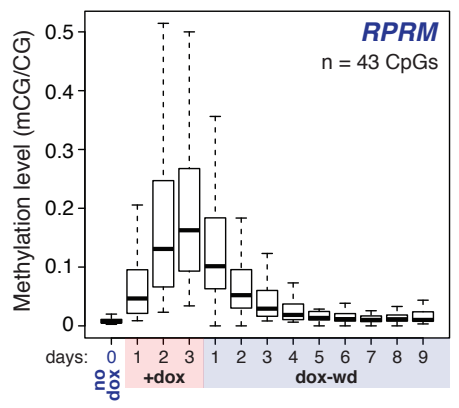

B

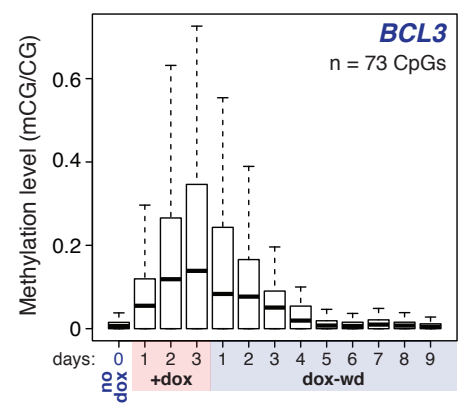

E

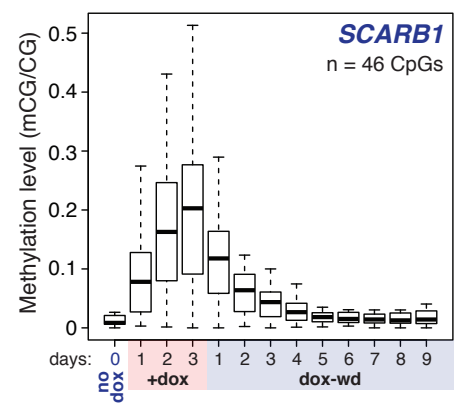

C

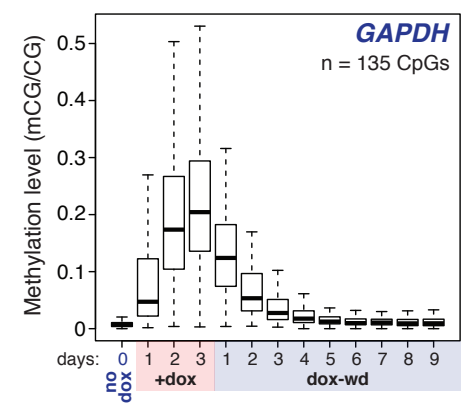

$F$

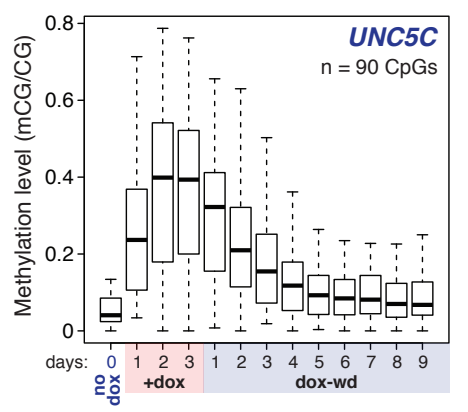

G

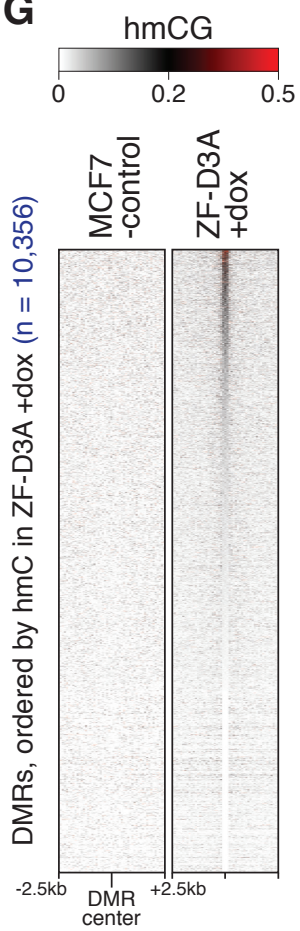

Supplementary Fig. S3.

(A to F) Box and whisker plots of the DNA methylation levels of the CpG sites in the promoter regions of six selected genes throughout doxycycline induction and withdrawal in the ZF-D3A cell line. Whiskers indicate 1.5 times the interquartile range or the most extreme data point, whichever is lower. (G) Heatmap of hmCG levels flanking ( $\pm 2.5 \mathrm{~kb}, 50 \mathrm{bp}$ bins) the centre of the DMRs, ordered by DMR hmCG level in ZF-D3A +dox cells. 
bioRxiv preprint doi: https://doi.org/10.1101/170506; this version posted September 20, 2017. The copyright holder for this preprint (which was not certified by peer review) is the author/funder, who has granted bioRxiv a license to display the preprint in perpetuity. It is made available under aCC-BY-NC-ND 4.0 International license.
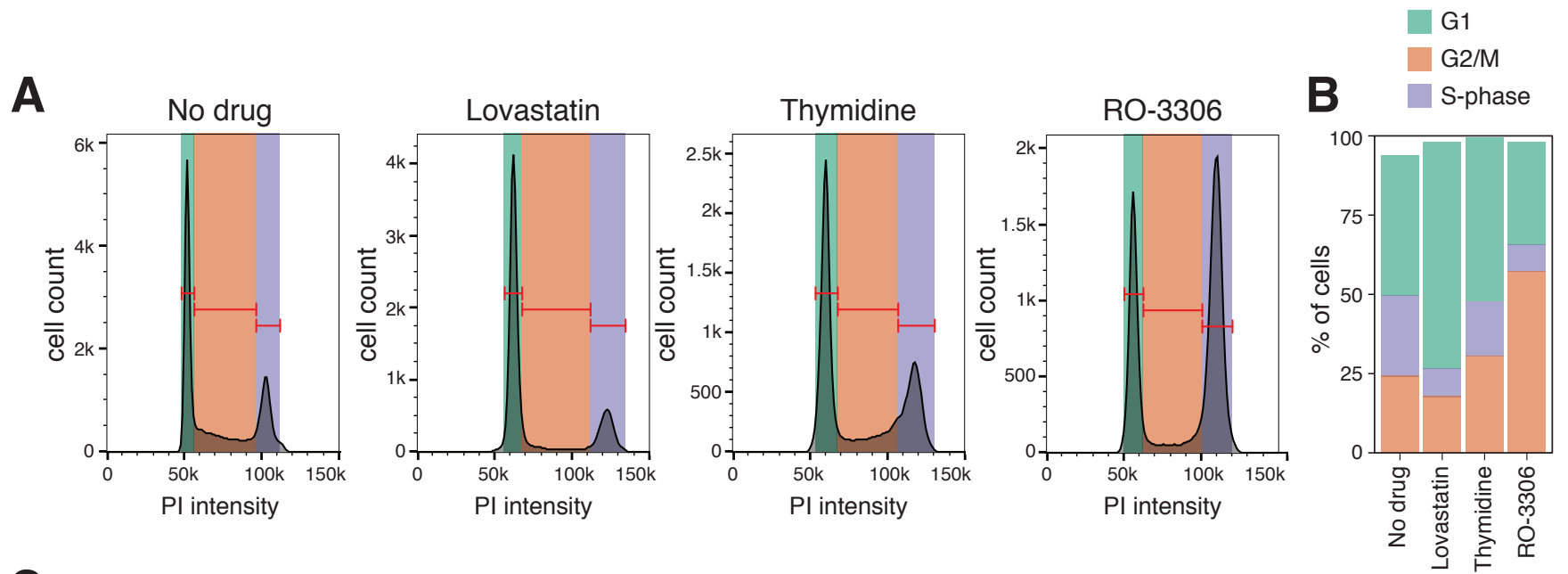

C
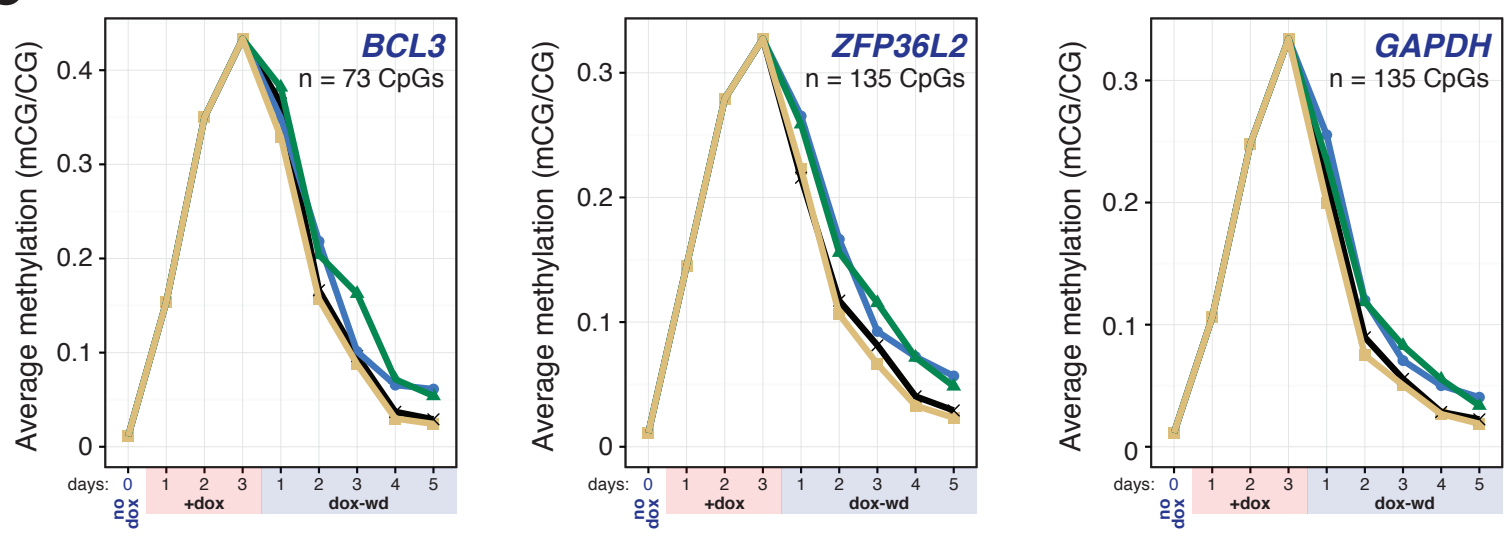

- No Drug
$\times$ Lovastatin
- RO-3306
- Thymidine
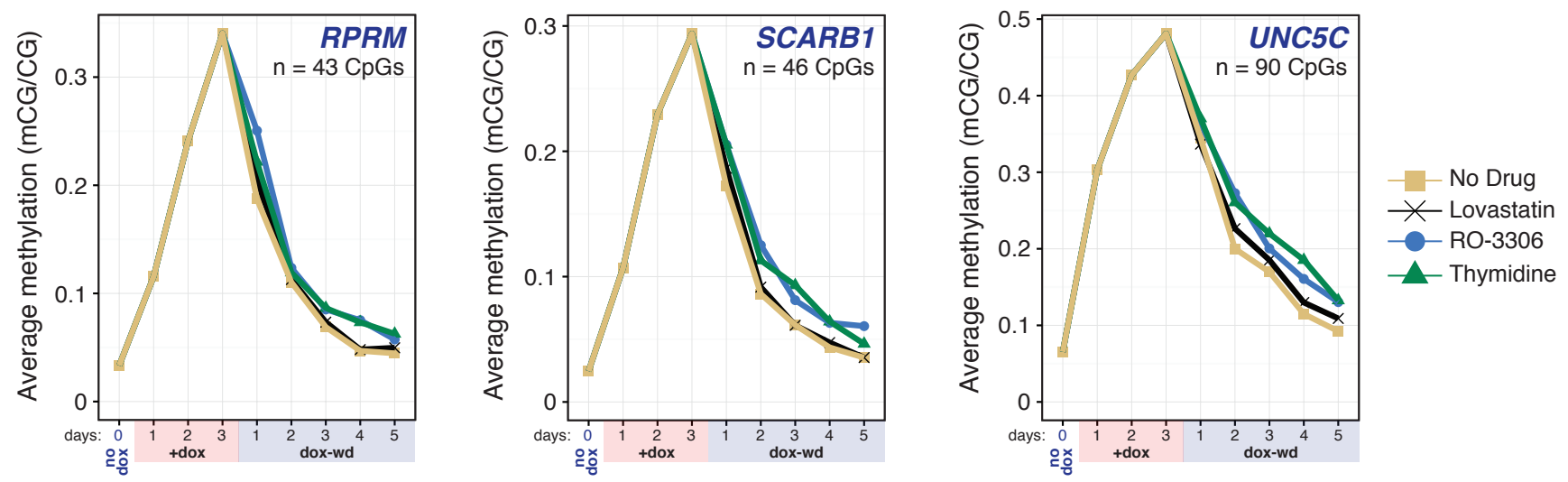

\section{Supplementary Fig. S4.}

(A) FACS analysis of propidium iodide stained MCF7-ZF-D3A cells that had been grown with and without treatment with cell cycle inhibitors. (B) Cell cycle distribution before and after cycle inhibitor treatment. (C) Average DNA methylation level at the $\mathrm{CpG}$ sites in the promoter regions of six selected genes throughout doxycycline induction followed by doxycycline withdrawal and cell cycle inhibition by growth in doxycycline-free media containing different cell cycle inhibitors (Lovastatin - G1 block; thymidine - S-phase block; RO-3306 - G2/M block) and an untreated (no drug) control. 


\section{Ford et al. Supplementary Figure 5}

bioRxiv preprint doi: https://doi.org/10.1101/170506; this version posted September 20, 2017. The copyright holder for this preprint (which was not certified by peer review) is the author/funder, who has granted bioRxiv a license to display the preprint in perpetuity. It is made available under aCC-BY-NC-ND 4.0 International license.
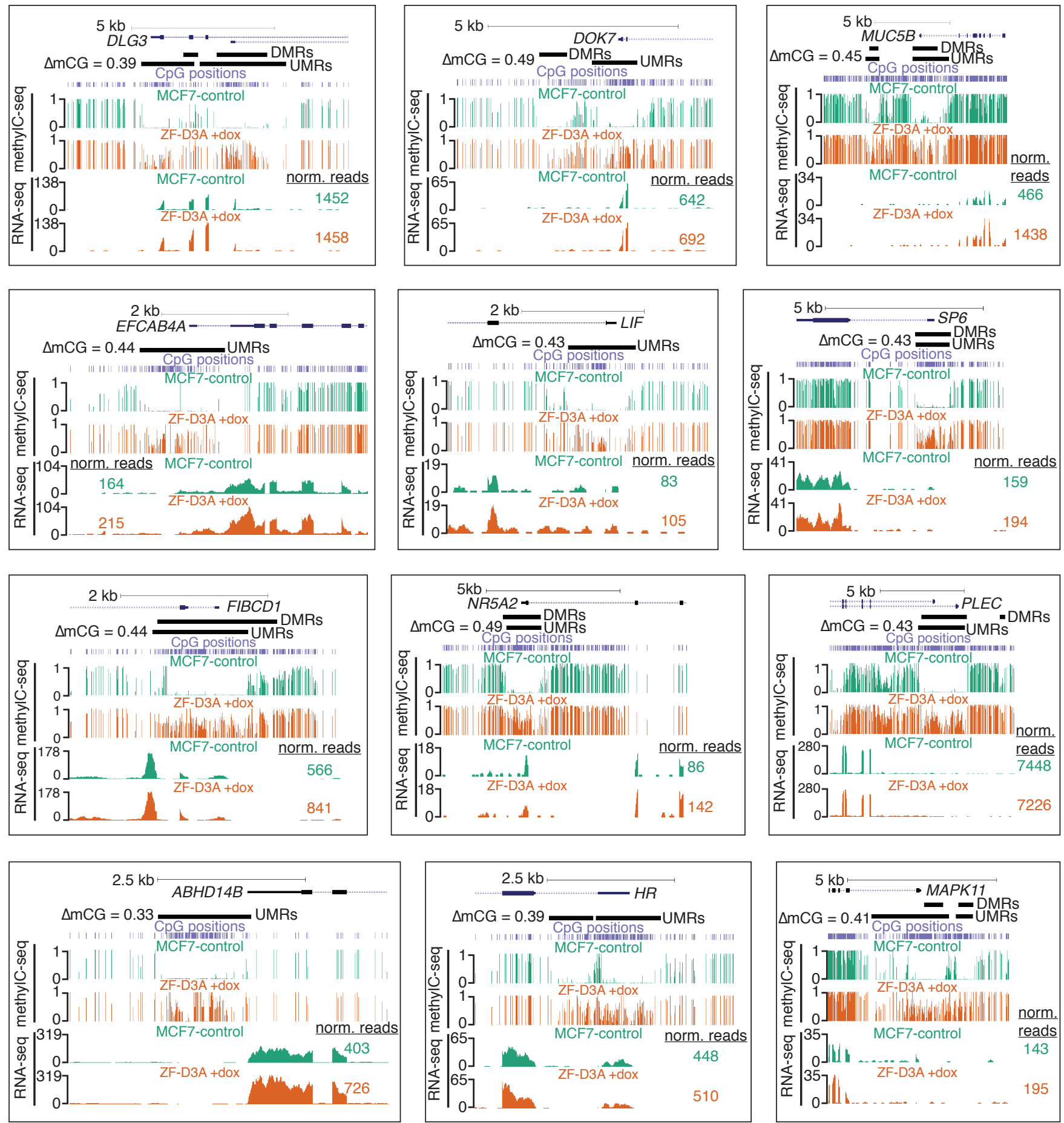

\section{Supplementary Fig. S5.}

Genome browser screenshots showing DNA methylation sites and levels and RNA expression signal (RNA-seq) for genes with high induction of promoter DNA methylation in ZF-D3A +dox and no reduction in mRNA abundance. 
bioRxiv preprint doi: https://doi.org/10.1101/170506; this version posted September 20, 2017. The copyright holder for this preprint (which was not certified by peer review) is the author/funder, who has granted bioRxiv a license to display the preprint in perpetuity. It is made available under aCC-BY-NC-ND 4.0 International license.
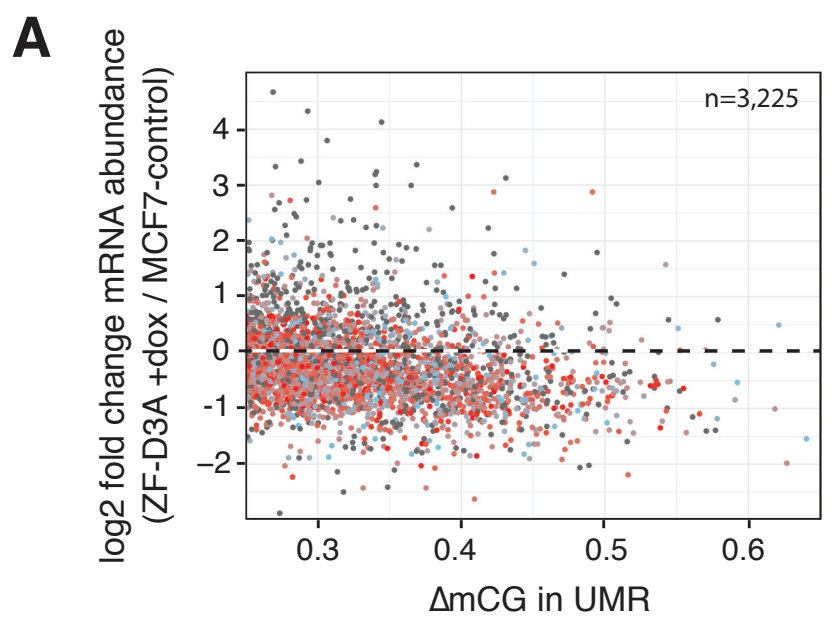

(ZF-D3A +dox - MCF7-control)
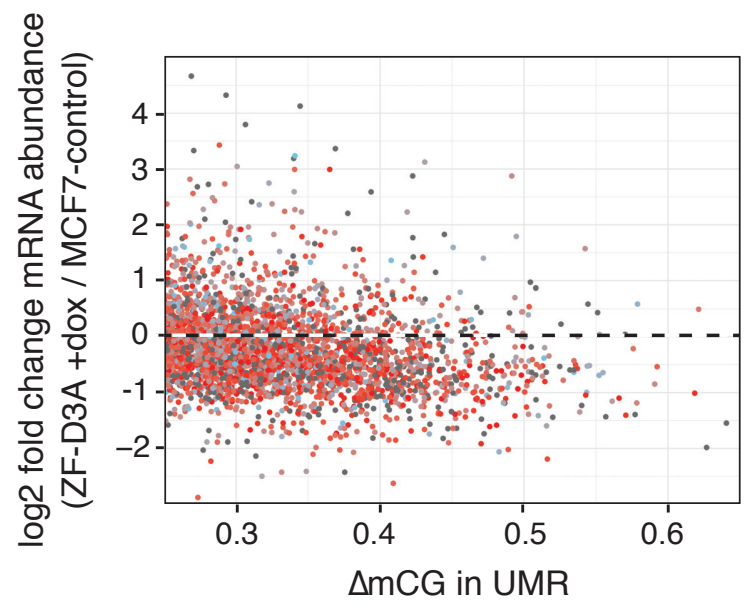

(ZF-D3A +dox - MCF7-control)
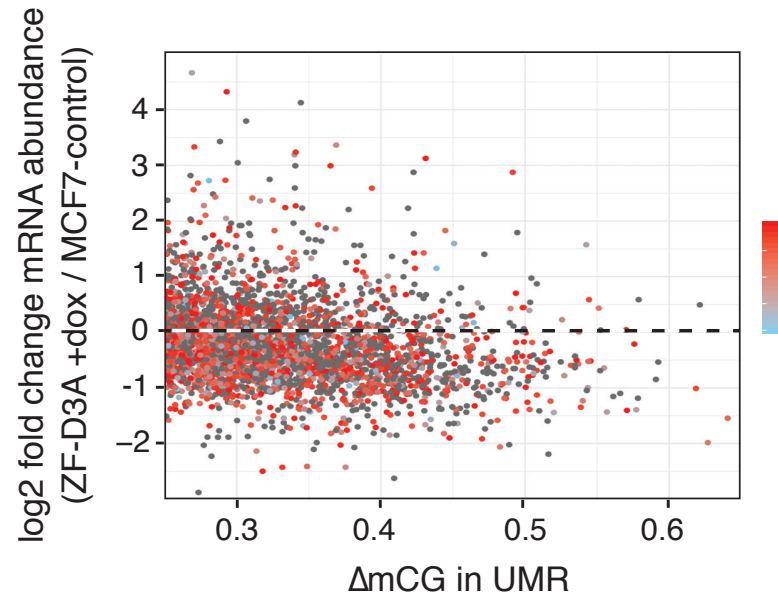

(ZF-D3A +dox - MCF7-control)
B
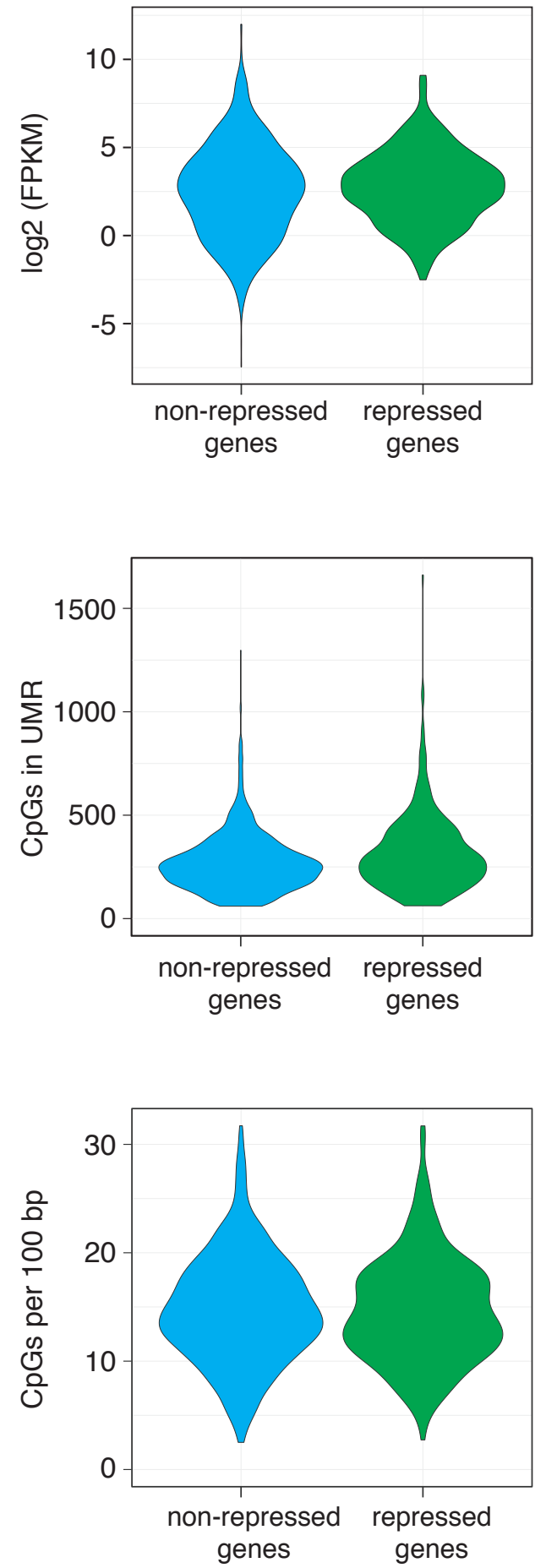

\section{Supplementary Fig. S6.}

(A) Scatter plot of the difference in UMR DNA methylation levels, versus the fold change in mRNA abundance of UMR-associated expressed genes, between MCF7-control and ZF-D3A +dox. Point color indicates relevant UMR feature quantitation. Repression of transcription following induction of ZF-D3A does not correlate with gene expression level (top), number of $\mathrm{CpG}$ dinucleotides in the UMR (middle), or CpG density in the UMR (bottom). (B) UMRs with a $\triangle \mathrm{mCG}>0.25$ were divided into repressed and non-repressed genes. Genes in the repressed and non-repressed categories were required to have a log2 fold change of less than -1 or greater than -0.1 mRNA abundance between the MCF7-control and ZF-D3A +dox data sets, respectively. 